\title{
Reexamen crítico de la biografía del humanista Sebastián Fox Morcillo (c. 1526- c. 1560) ${ }^{1}$
}

\author{
Alejandro Cantarero de Salazar \\ Instituto Universitario Menéndez Pidal \\ Universidad Complutense de Madrid \\ acsalazar@ucm.es
}

Recepción: 23/01/2015, Aceptación: 14/05/2015, Publicación: 22/12/2015

\begin{abstract}
Resumen
El presente trabajo estudia la vida del humanista sevillano Sebastián Fox Morcillo (c. 1526- c. 1560). Partimos del análisis de las fuentes primarias y secundarias para establecer un exhaustivo estado de la cuestión y añadir algunas referencias olvidadas. También se examinan algunos aspectos de la biografía de su hermano Francisco Morcillo, para intentar esclarecer la posible persecución de Sebastián Fox Morcillo por parte de la Inquisición.
\end{abstract}

Palabras clave

Humanismo; Sebastián Fox Morcillo; Francisco Morcillo; Inquisición

\begin{abstract}
Critical review of the biography of the humanist Sebastian Fox Morcillo (c. 1526-c. 1560) This paper studies the life of the Seville humanist, Sebastian Fox Morcillo (c.1526-c. 1560 ). It starts with an analysis of primary and secondary sources to establish a comprehensive account of his life, and adds some forgotten references. Some aspects of the biography of his brother, Francisco Morcillo, are also studied in an attempt to clarify Sebastián Fox Morcillo's possible persecution by the Spanish Inquisition.
\end{abstract}

\section{Keywords}

Humanism; Sebastián Fox Morcillo; Francisco Morcillo; Inquisition

1. Este trabajo ha sido realizado en el marco del proyecto Inventario, descripción, edición critica y análisis de textos de prosa hispánica bajomedieval y renacentista. Linea Diálogos. Fase 3 (FFI201233903) del Instituto Universitario Menéndez Pidal (UCM) y durante el disfrute de un contrato predoctoral para la formación de doctores (BES-2013-062592) en el marco del citado proyecto. Una estancia en la Universidad de Reims concedida por el MINECO (EEBB-I-15-10455) me ha permitido la consulta directa de varios libros en la Biblioteca Nacional de Francia. 
«De uno de estos filósofos voy a daros idea, aunque somera y breve. No dudo que su nombre sonará extraño en muchos oídos. Sebastián Fox Morcillo (que así se llama el varón insigne a quien aludo) ha sido poco afortunado en punto a lograr biógrafos y comentadores, sin embargo de merecerlo tanto o más que otro cualquiera de los maestros del pensamiento ibérico (exceptuados los Dii Majores, Séneca, Averroes y Maimónides, Lulio, Vives y Suárez). La mayor parte de los sucesos de su vida permanecen envueltos en nieblas; todo lo que de él nos dicen nuestros bibliógrafos y críticos, cabe en muy pocas líneas. Sus libros son $\tan$ extraordinariamente raros, que quizá no hay biblioteca en Europa que los posea todos, y, por supuesto, nadie se ha cuidado de reimprimirlos en colección ordenada y correcta, que a tanto alcanza nuestra proverbial incuria. ¿Qué más? El sapientísimo filósofo que ocupa la Sagrada Cátedra de San Isidoro ofreció, no ha mucho, un premio para el autor de la Memoria en que mejor se expusieran las doctrinas de Sebastián Fox Morcillo. ¿Creeréis que allí, en la culta Sevilla, en la cuna misma de este clarísimo ingenio, nadie ha respondido al llamamiento del ínclito Prelado?» (Laverde Ruiz, 1933: 222-223)².

Desde finales del siglo XIX varios fueron los intelectuales que señalaron la desatención hacia una de las figuras más destacadas y productivas de nuestro humanismo: Sebastián Fox Morcillo. Estas exhortaciones animaron sin duda a todos los que desde entonces han trabajado - a partir de muy diversas perspectivas - sobre este polígrafo del siglo XVI.

La figura del filósofo español fue destacada también en épocas tempranas dentro del conjunto de Europa. Auberto Mireo (1609: 126) —al hablar de Cornelio Valerio- refiere a Fox Morcillo como el más elocuente de los filósofos de su época. Por otro lado, Gabriel Naudé (1633: 16) lo cita junto a tres figuras de gran relevancia para el humanismo renacentista: Pontano, Erasmo y Vives. Más adelante, lo refiere Adrien Baillet (1683: 137-140; y 1722: 75-76) y no se limita a citar su nombre, sino que incluye una breve biografía del autor, destacándolo como joven humanista y precoz en sus estudios. De nuevo encontramos una síntesis de su vida — de menor rigor, pero también cargada de elogios - en la obra de Jacob Brucker (1742-1767: t. IV, I parte, 766-767)3.

La biografía del filósofo hispalense ha sido estudiada de forma parcial —ya sea en publicaciones periódicas o monografías- y englobada en estudios sobre el pensamiento del autor o en ediciones críticas de su obra. No obstante, de entre estos trabajos una serie de ellos intentan presentar de forma sistemática la biografía

2. Cabrero (2012: 1) asegura que este discurso fue escrito por Menéndez Pelayo, quien colaboró con su joven y enfermo maestro para que pudiera acabar varios de sus proyectos. A pesar de ello, a lo largo del trabajo citaré el discurso bajo la autoría de Laverde Ruiz, tal como consta en la publicación. En 1884 la Real Academia Sevillana concedió un premio a un primer ensayo sucinto sobre la obra y la vida de Fox de José Bores y Lledó (1884: 262-293).

3. Jacob Brucker (1742-1767: t. IV, I parte, 766) dice erróneamente que Fox Morcillo nace en Toledo. 
del autor ${ }^{4}$. Incluso, contamos con varias entradas sobre Sebastián Fox Morcillo en dos diccionarios biográficos recientes (Pineda, 2009-2012; y Espigares, 2012) 5 .

No obstante, la complejidad de la reconstrucción de la vida del filósofo sevillano, el paso del tiempo de muchos de los trabajos que se dedicaron en exclusiva a su biografía, así como la falta de sistematización, hacen necesario un trabajo que reúna y analice toda la información recabada. Nuestro objetivo es, por tanto, el acopio de toda la bibliografía secundaria que ha versado sobre la vida de Fox Morcillo, analizando críticamente la información, en contraste con las pocas fuentes primarias que hemos conservado sobre su vida. Incluso, el acopio exhaustivo de bibliografía nos ha llevado a descubrir fuentes coetáneas a Fox Morcillo, hasta ahora obviadas por la crítica. En definitiva, la revisión completa y sistematizada de la bibliografía referida a Fox Morcillo es el único camino para intentar desentrańar muchos de los oscuros pasajes de su vida.

\section{Juegos literarios, apostillas manuscritas y testimonios contradictorios: el problema de las fuentes documentales sobre la vida de Fox Morcillo}

Dentro de la información que nos ha llegado sobre el hispalense debemos distinguir, antes de nada, entre dos tipos de fuentes: las que proceden directamente de Sebastián Fox Morcillo y las noticias que nos ofrecen otros personajes de su época, con mayor o menor proximidad al autor.

En primer lugar, de entre las fuentes directas que proceden del autor, nos topamos con una emocionante sorpresa: varios ejemplares anotados de su mano. Se trata de documentos de gran importancia que pueden desvelarnos conjeturas de su biografía y mostrarnos muchas de las lecturas realizadas por Fox Morcillo, sus opiniones filosóficas y, en definitiva, el poder imaginar cómo fue el trabajo diario para alcanzar su gran formación intelectual. Sobre esta labor de Fox de comentarista y exégeta no existe un trabajo que reúna todas las obras conservadas, sino dos trabajos independientes.

En un primer estudio, José Luis Gonzalo Sánchez-Molero (2002) se ocupa de los ejemplares conservados en la Biblioteca de El Escorial de distintas procedencias. Este autor distingue dentro de las obras custodiadas en la Escurialense dos grandes grupos. En primer lugar, las obras impresas, cuyo autor es Fox Morcillo y dedicadas de su mano a varios nobles que lo protegieron (Felipe II, el cardenal Francisco de Bobadilla o Francisco de Mendoza, Diego Hurtado de Mendoza y el marqués de Vélez, Pedro Fajardo). En segundo lugar, los libros de

4. Solo cito, por el momento, los estudios más completos en el aspecto biográfico: González de la Calle (1903: 12-26); Pineda (1994: 47-65) y Espigares (1994: 219-233).

5. Pineda (2009-2012: 533) transmite de forma errónea una supuesta traducción de la obra $D e$ honore de Fox Morcillo al francés por F. Baraud, Paris, 1559 y su posterior traducción al español por González de la Calle (1903: 315-352). Ambas traducciones - la primera de ellas perdidacorresponden a la obra latina de Fox Morcillo De iuventute. 
estudio anotados que Fox empeñó a Benito Arias Montano en Sevilla de 1558 y que este a su vez cedió a la biblioteca de El Escorial. De entre los ejemplares escurialenses los que pertenecieron a Arias Montano nos dejan otra fuente primaria de su vida, aunque a partir de una cita en el tercer inventario de sus bienes: la noticia de la cédula de empeño de los libros firmada por Fox en Sevilla el siete de diciembre de $1558^{6}$.

Gonzalo Sánchez-Molero (2002) no tuvo en cuenta la existencia en la Biblioteca Nacional de España de un interesante volumen facticio al que años después Mélanie Jecker (2012) dedicó un artículo. En este segundo trabajo estudia el volumen facticio de la Biblioteca Nacional de España (R/25106). Se trata de un libro con una anotación manuscrita de posesión de Sebastián Fox Morcillo en la primera obra que incluye el volumen y plagado de anotaciones en la totalidad de las obras encuadernadas juntas ${ }^{7}$.

A pesar de que Mélanie Jecker considera que es la primera en dar noticia de este libro desconocido, he encontrado una referencia a la pertenencia del volumen al filósofo hispalense y a sus anotaciones en un trabajo anterior, de Luis Robledo (2005: 14). En él Robledo se refiere a las anotaciones que Fox Morcillo había tomado en la Política de este volumen facticio. Por otro lado, el trabajo de Jecker no tiene en cuenta lo expuesto por Gonzalo Sánchez-Molero ni la colección de apostillas de El Escorial. Estas colecciones de textos glosados por el autor merecerían un estudio específico de conjunto, que extrajera toda la información sobre el humanista reconstruyendo sus lecturas a partir de las anotaciones que se nos han conservado.

Un documento que debemos también tener en consideración, dentro de las fuentes directas, serían los libros de matrícula de la Universidad de Lovaina, a los que me referiré más adelante ${ }^{8}$. Finalmente, un texto de gran interés y recuperado no hace mucho tiempo por los Avisos de la Real biblioteca: una carta de Fox al cardenal Granvela, el 26 de noviembre de 1556 (Real Biblioteca, Año XI, Nº. 41, abril - junio, 2005).

Debemos sumar a estas fuentes la información biográfica que Sebastián Fox Morcillo incluye en su obra, una de las más empleadas para la reconstrucción de la vida del hispalense. Sin embargo, respecto a esta cabe hacerse la siguiente

6. Este documento aparece recogido en dos publicaciones: Rodríguez-Mońino (1928) — quizás más fácilmente asequible-y Rodríguez Marín (1923).

7. El ejemplar, con signatura R-25106, contiene: (1) Aristotelis de Republica Libri VIII. Interprete et enarratore Io. Genesio Sepulveda Cordubensi, Parisiis, Apud Vascosanum, via Iacobea, ad insigne Fontis, 1548; (2) Aristotelis ad Nicomachum filium de Moribus, que Ethica nominatur, Libri decem, Ioachimo Perionio Benedictino Cormoeriaceno interprete. Commentarii eiusdem in eosdem libros, in quibus de convertendis coniungendisque Graecis cum Latinis praecepta traduntur, Parisiis, Apud Thomam Richardum, sub Bibliis aure is, e regione Collegii Remensis, 1549; (3) Aristotelis et Xenophontis oeconomica, Ab Iacobo Lodoico Strebaeo e Graeco in Latinum conuersa, Lutetiae, Apud Vascosanum, via Iacobaea ad insigne Fontis, 1551; y (4) Ioachimi Perionii Benedict. Cormoeriaceni de optimo genere interpretandi commentarii, Parisiis, Apud Simonem Colinaeum, 1540.

8. Editados modernamente en: Schillings (1961, vol. IV, 389, n 125). 
pregunta: ¿hasta qué punto podemos considerar infalible la información transmitida en lo que es un ejercicio literario?

Considero que este interrogante no ha sido planteado por muchos de los estudiosos actuales de Fox, sino que adjudican al autor sevillano toda la información que el autor puso en boca de sus personajes, no hay que olvidarlo literarios? No obstante, vemos claramente una oposición a este respecto en el caso de su diálogo De imitatione, donde se caracteriza al personaje ausente de Sebastián Fox - podríamos pensar alter ego del autor- con unas opiniones muy alejadas a su pensamiento real. Para justificar que el personaje de Francisco necesite aprender de Envesia las cuestiones del ornato y no las haya aprendido de su hermano - como sería lógico- Francisco presenta a Sebastián como desinteresado en el adorno del discurso: «Frater enim contemplationi cognitionique rerum admodum intensus aut orationis ornatum plane contemnit aut ei minus dandam esse operam putat ${ }^{10}$.

Sin embargo, como podemos ver en los tratados de Sebastián Fox Morcillo, más concretamente en sus cuatro diálogos, el adorno del discurso e, incluso, el que su escritura constituyera una obra de arte, fue una de las principales preocupaciones del filósofo sevillano.

Reparar en este fragmento nos permite plantearnos la necesidad de contrastar toda la información que Fox transmite de su propia vida en sus obras, pues si la subjetividad es difícilmente salvable, lo es aún más cuando se recubre de proyecciones literarias. Existe una tendencia a ignorar el carácter de personajes literarios para aquellos que llevan el mismo nombre del autor, un hecho común en el diálogo renacentista. Unos pueden acercarse a un retrato que coincide con lo que sabemos por otros caminos, pero otros no, y las distorsiones significativas tendrán siempre valor argumentativo. Piénsese, sin más, en el autorretrato que Juan de Valdés hace de sí mismo en el Diálogo de la lengua. Por ello, deberemos analizar con cuidado toda la información que encontramos sobre el autor en sus textos, contrastándola con otras fuentes antes de incluirla dentro del capítulo de la biografía de Fox.

Pasando al segundo grupo de fuentes transmitidas sobre la vida de Fox nos encontramos con varios y muy contradictorios testimonios de época, sobre todo en lo que respecta al episodio de su muerte: las cartas XVI y XvIII del epistolario de Languet ${ }^{11}$, dirigidas a Philippo Melanchthon la primera y a Ulricho Mordi-

9. La mayoría de estudios sobre la obra de Fox Morcillo no reparan en los aspectos literarios de sus cuatro diálogos. A este respecto véase: Cantarero (2015a).

10. «Mi hermano, encaminado enteramente a la contemplación y conocimiento de las cosas, desprecia por completo el adorno del discurso, o piensa que apenas hay que dárselo a la obra». Cito todos los pasajes de De imitatione, tanto en latín como en español, a partir de la edición bilingüe: Pineda (1994, 134 —edición latina- y 182 — traducción española-). En lo sucesivo se citará, a no ser que se indique lo contrario, a partir de esta edición, correspondiendo la primera página o grupo de páginas a la ed. latina y el segundo a la traducción al castellano.

11. Hubertus Languetus, 1699: epístola XVI (pp. 40-42) y epístola XvIII (pp. 45-47). 
sio la segunda; el testimonio de Andrés Escoto en Hispaniae Bibliotheca, que se opone a estas como veremos; y por último, la más reveladora: la declaración de Fray Baltasar en el llamado Proceso de Carranza.

Lejos de pretender analizar ahora estas fuentes, que serán tratadas en su momento y contrastadas para intentar reconstruir una idea lo más cabal de la vida de Fox Morcillo, quería simplemente presentarlas dentro del conjunto de las fuentes documentales empleadas, para hacernos una ligera idea de los datos conservados sobre el autor hispalense y de la necesidad de interpretarlos críticamente.

\section{La vida de Sebastián [Morcillo] Fox: humanismo, heterodoxia y clandestinidad}

Sebastián Fox Morcillo, latinizado por él mismo como Sebastianus Foxius Morzillius $^{12}$, nació entre 1526 y 1528 en Sevilla. Según dice Rodrigo Caro (1992: 86) ${ }^{13}$, que a su vez recibe la información de Francisco de Medina, nacería en la Calle de Las Palmas ${ }^{14}$ y sería bautizado en la parroquia de San Miguel, sin encontrar más fuente para aseverar que naciera en dicha calle y que su partida de bautismo constase en esta parroquia ${ }^{15}$. Andrien Baillet lo describe como infatigable en sus estudios a pesar de su tierna juventud y delicada complexión ${ }^{16}$.

12. González de la Calle (1903: 12) señala otras variantes de su nombre: Foxo y Foxio Morcillo. En todas sus obras aparece su nombre latinizado: Sebastianus Foxius Morzillus. La latinización del nombre y los apellidos era común en los humanistas del período. Respecto a la forma latina del nombre de Hernando de la Torre, Ferdinandus Arcaeus, explica Bécares (2003) un error muy extendido en los catálogos bibliográficos: considerar a Fernando de Arce — a partir de Ferdinandus Arcaeusun autor distinto de Hernando de la Torre (nombre original en español). En cuanto a las formas no latinizadas del nombre de Fox Morcillo, también encontramos — sobre todo en autores extranjerosla forma «Morzillo». Lueben (1914: 1) da como variante "Mirzillus» a partir de Languet (1699, Libro II, ep. xvi: 41), aunque también podría ser una errata, ya que solo se ha constatado en este lugar.

13. Aunque la obra quedó incompleta y manuscrita, Gómez Canseco la editó en el siglo xx. Sin embargo, en lo que respecta a la información sobre Fox Morcillo, ya González de la Calle (1903: 303-306) transcribió al completo los datos de la biografía de Fox elaborada por Rodrigo Caro.

14. Pike (1968: 878) propone Santa María, como barrio natal de Fox Morcillo, lugar que cree que habitaban sus supuestos padres por la fecha en la que nacería. Sobre el nacimiento en la Calle de las Palmas - propuesto por Rodrigo Caro- comenta que el dato no ha sido apoyado por ningún documento, llamando la atención sobre la situación del palacio del Duque de Medina Sidonia en San Miguel, Plaza del Duque, cerca de la Calle de las Palmas (Pike, 1968: 881). La misma autora vuelve a proponer el mismo lugar de nacimiento para Sebastián Fox: «Probablemente, Sebastián había nacido del matrimonio cuando este todavía vivía en Gradas, el distrito comercial de Sevilla en el barrio de Santa María. Parece que la familia cambiaba de domicilio con frecuencia. En 1534 estaban en la lista de residencias de la parroquia de San Ildefonso; cinco años más tarde estaban viviendo de nuevo en una casa alquilada en Gradas» (Pike, 1978: 157).

15. Puesto que la obligatoriedad de llevar archivos parroquiales se estableció en el Concilio de Trento y la disposición no llegó a España hasta 1564, no es sencillo dar con dicha partida. (Espigares, 1994: 224). 16. «Les éxercises de ses études étoient continuels, et on l'a toujours trouvé infatigable malgré la tendresse de son âge el la délicatesse de sa complexion» (Baillet 1688: 138 ). Sin embargo, no cita la fuente de un dato tan preciso como la complexión de Fox Morcillo. 
El primer dato que presenta problemas sería el año de su nacimiento que para casi todos los biógrafos y estudiosos de Fox se sitúa en 1526. Se trata de una cifra extraída de la propia obra de Sebastián Fox Morcillo, más concretamente de De iuventute: «Nunc autem vix annum, ut scis XXVIII ago ${ }^{17}$ ».

Las primeras referencias biográficas ubican el nacimiento de Fox en $1526^{18}$, año obtenido de restar a 1556 - fecha que consta en el colofón de De iuventutelos veintiocho años que dice tener en el momento del diálogo. Es González de la Calle (1903: 13-15) quien repara en que el dato está inserto en una serie de juegos literarios que crean el marco dialógico de De iuventute. Este planteamiento, como ya hemos señalado, no puede ser obviado: la información biográfica de Fox está en unos textos de carácter literario. Aunque la mayoría de la crítica ha dado de lado a los interrogantes de González de la Calle, o los han reducido a una nota a pie de página, creo de suma importancia el revisarlos y planteárnoslos de nuevo. En primer lugar, González de la Calle repara en que el coloquio en De iuventute está ambientado en una época pasada, licencia nada ajena a los textos literarios. Solo la epístola nuncupatoria (págs. 3-5) se referiría a 1556, mientras que el resto del diálogo se localiza temporalmente a partir de la creación del espacio literario:

Cum post diuturnam a patria peregrinationem, vehementi meorum desiderio incesus, Franciscum fratrem, egregie, in studiis versatum iuvenem, aliquando per literas Lovanium evocassem: atque is eo tempore, quo Philippus Hispaniae princeps in Angliam foelicissima navigatione appullit (Fox Morcillo, 1556: 6) ${ }^{19}$.

Es decir, el diálogo se ubica, como expresa González de la Calle (1903: 1315), junto con el hecho histórico citado: la llegada de Felipe II a Inglaterra para casarse con María Tudor, acontecimiento que tuvo lugar en 1554. No me parece nada descabellado el pensar que la edad del personaje de Sebastián Fox sea la que este tenía en 1554 y no en 1556 , como la mayoría de la crítica señala. Se trataría de un rasgo más de caracterización del personaje, como hemos indicado al hablar de las fuentes biográficas literarias, que habría que tener en cuenta a la

17. «En cambio ahora, como sabes, tengo apenas veintiocho años» (Traducción mía, Fox Morcillo, 1556: 33).

18. Hay que señalar que tanto Escoto (1608: 453-456) como N. Antonio, (1783-1788: tomo I, pp. 280-281), escriben «circa 1528» y dicen obtener la fecha de la obra De imitatione. Sin embargo, Caro (1992: 87), escribe simplemente «1528» y confiesa obtener la información de Escoto. Arana de Varflora (1791: 91-93) también señala como fecha de nacimiento «1528». Kuiper (1941: $185)$ indica que Fox nació «alrededor de 1527». Jöcher (1750, t. 3: 695) y Lueben (1914:1) dan como fecha «1528», siguiendo ambos la opinión más divulgada.

19. «En cierta ocasión y después de larga ausencia de la patria, movido del ardiente deseo de ver á los míos, llamé por cartas á Lovaina á mi hermano Francisco, joven admirablemente versado en los estudios: este vino en la misma escuadra que tras felicísima navegación condujo á Inglaterra á Don Felipe, Príncipe de España» Cito el texto latino de Fox Morcillo (1556: 6) y la traducción española del pasaje en González de la Calle (1903: 317-318). En lo sucesivo se citará el original latino De iuventute de esta edición y la traducción de González de la Calle ya referenciada. 
hora de documentar la biografía de Fox Morcillo. Por ello, algunos autores prefieren señalar que el filósofo nacería entre 1526 - fecha deducida de la resta de veintiocho a 1554 - y 1528, primera fecha propuesta, pensando que el diálogo está encuadrado en la misma fecha del colofón $(1556)^{20}$.

Ante estos datos resulta difícil señalar una fecha precisa para el nacimiento del filósofo español, a no ser que encontráramos su partida de bautismo en la citada parroquia de San Miguel. A este respecto fue Espigares Pinilla (1994: 223-224) quien comprobó los libros de bautismo, pero el primero de los conservados se refiere a los ańos 1539-1552. Tendremos que conformarnos pues, con el marco temporal de 1526-1528, a la espera de que aparezcan nuevos documentos. Sin embargo, de ninguna manera deberían desecharse las dudas nada inverosímiles expuestas por González de la Calle, para tratar de fijar una fecha determinada.

La ascendencia de Sebastián Fox Morcillo constituye, al igual que su fecha de nacimiento, otro capítulo oscuro de su biografía. No obstante, el estudio realizado por Pike (1968) vino a desvelar el elaborado secreto del humanista español. Como se había señalado en las biografías de Fox anteriores a este artículo, el propio autor repasa su alcurnia en De imitatione (1554) en boca del personaje de su amigo Envesia, en un pequeño excursus al hablar de la decadencia del latín a partir del imperio de Teodosio:

Gottis enim Italia pulsis in Galliam, indeque postea per eam Aquitaniae partem (cui Foxii comites tui, Francisce, gentiles, e quorum familia maiores tui origine ducta, in Hispaniam Tarraconensem initio, in Baeticam postea migrantes progressu temporis Hispali sub Ferdinando V Hispaniae rege consedere, summa cum gloria diu imperarunt)...(Pineda, 1994: 144) ${ }^{21}$.

El primer biógrafo de Fox, Andrés Escoto, parafrasea esta información al estudiar la genealogía de Fox Morcillo:

Nobilis autem ut in Gallia, sic et in Hispania Foxiorum gens, quae cum Gothis Italia pulsis in Aquitaniam primum (ubi et Foxii summa cum gloria diu imperarunt) post in Hispaniam Tarraconensem mox in Baeticum migrans, temporis progressu Hispali sub Ferdinando V Hispaniae Rege consedit (Escoto, 1608: 453-454) ${ }^{22}$.

20. Mantienen ambas fechas Pike (i 968: 877) y Cortijo Ocaña (2000: 69). Por otro lado, Truman (1986: 283) señala un período más abierto: «born at Seville in the late 1520s».

21. "Después, cuando los godos fueron expulsados de Italia a la Galia y más tarde, a través de Aquitania (de donde es originaria tu estirpe, que allí rigió con suma gloria por mucho tiempo, y desde donde tus parientes los Fox llegaron a Hispania, primero a la Tarraconense y luego, al pasar el tiempo, a la Bética, para establecerse finalmente en la ciudad de Hispalis bajo el reinado de Fernando V)...» [La negrita es mía]. (Pineda 1994: 195).

22. «Fue noble tanto en la Galia como en España la familia de los Fox, la cual, emigrando con los godos expulsados de Italia primero a Aquitania (donde también los Fox dominaron largo tiempo con gran gloria) después a la Hispania tarraconense y luego a la Bética, se asentó pasado el tiempo en Hispania bajo el reinado de Fernando V» (Traducción mía). 
Este linaje del autor sevillano siguió siendo reproducido sin el menor atisbo de dudas por el resto de biógrafos: Rodrigo Caro (1992), Nicolás Antonio (17831788, v. II, 280), etc. Sin embargo, Laverde Ruiz introduce algún dato novedoso:

«En cuanto a su linaje, el mismo Fox Morcillo nos advierte, en su diálogo De informandi styli ratione, que derivaba de la nobilísima alcurnia provenzal de los condes de Foix, a la cual pertenecía, bien que algo remotamente, uno de los caballeros franceses que asistieron a la conquista de Sevilla con San Fernando. Esta noticia, confirmada por Rodrigo Caro, deshace todas las dudas acerca del verdadero apellido de nuestro filósofo, que es, sin duda, Fox (corruptela de Foix), aunque tampoco deban rechazarse las variantes latinizadas Foxo, Foxio...» (Laverde Ruiz, 1933: 224).

Finalmente, en González de la Calle (1903: 16) observamos de nuevo la asunción de las palabras de Nicolás Antonio, al que reivindica, y las del propio Fox en su obra. Sin embargo, critica la relación establecida por Laverde Ruiz con «uno de los caballeros franceses que asistieron á la conquista de Sevilla con San Fernando", dato que no ofrecía ni Rodrigo Caro ni Nicolás Antonio ni el propio autor, considerando una innovación, cuyo objetivo era relacionar a Fox con una de las familias más importantes de Sevilla. González de la Calle (1903: 16) llama la atención, al mismo tiempo, sobre el silencio que guarda el filósofo en lo que respecta a sus antepasados.

Efectivamente, el vacío de referencias reales sobre estos y la única noticia —inventada de nuevo desde la licencia de la argumentación dialógica — en $D e$ imitatione, aspiraban a cubrir con un tupido velo cualquier sospecha en cuanto a su limpieza de sangre.

Será el trabajo de Pike (1968) el que ponga palabras y nombres propios a toda esta oscuridad. La autora parte del análisis de los documentos del Archivo de Protocolos de Sevilla ${ }^{23}$. El estudio detenido de estos documentos permitió a Pike determinar que Sebastián Fox Morcillo falsificó sus antecedentes familiares para afirmarse descendiente de los condes de Foix.

En primer lugar, Sebastián Fox Morcillo invirtió el orden de sus apellidos, adelantando el materno «Fox» al «Morcillo» paterno, cuya ascendencia judeoconversa era muy difícilmente ocultable (Pike, 1968: 877-878)24. Para Pike

23. Gestoso y Pérez (1899/1900) y Archivo de Indias (1940-1946).

24. En la época era normal la elección de los appelidos: «Los procedimientos más frecuentes para evadirse de la clase social donde su origen y la opinión común los tenía encadenados eran cambiar de residencia y de apellidos; este segundo método era entonces mucho más sencillo que hoy porque no existía registro civil y reinaba bastante anarquía en el uso de apellidos; muchos cambiaban o anteponían el materno al paterno por motivos de prestigio, conveniencia o capricho» (Domínguez Ortíz, 1955: 375). No obstante, Pike no especifica si tenemos constancia de que el autor se llamara primero «Morcillo Fox», e invirtiera posteriormente el orden de los apellidos; o si, por el contrario, los eligió directamente en este orden, para ocultar su primer apellido de clara ascendencia judía. En la referencia en los libros de matrícula de la Universidad de Lovaina encontramos solo el apellido "Morchilio" (Schillings, 1961, vol. IV: 389, n 125) y -como veremos posteriormente- en la declaración de fray Baltasar en contra del hispalense se refiere a él como 
(1978: 156) el abuelo paterno de Fox Morcillo era Hernando Morcillo, calcetero de oficio, que habitaba en Santa María, según el censo de 1534. Este personaje aparece en la nómina de las Composiciones sevillanas de 1510, junto a Álvaro Morcillo, cuyo parentesco sigue siéndonos oscuro (Guillén, 1963). Hernando Morcillo es el padre, junto con Isabel de Carmona, de una serie de personas citadas frecuentemente en los documentos sevillanos analizados por Pike. Entre ellos aparece la figura del platero Francisco Morcillo. Como dos de sus hermanos, Juan y Gonzalo Morcillo, invirtió en el comercio transatlántico ${ }^{25}$, aunque su oficio fuese el de platero. Pike (1968: 878) explica que en 1541 parece ser que elaboró varios ornamentos de plata para la catedral e incluso tuvo un papel de importancia en la conformación del gremio de plateros sevillanos, la Cofradía de San Eligio, según suponemos de la constancia de su nombre en los estatutos de constitución del gremio en 1554 y después en 1556, como participante en un litigio emprendido por el gremio contra el gobierno de la ciudad.

Por lo tanto, Francisco Morcillo y su mujer Violante de Fox, serían los padres del filósofo español Sebastián Fox Morcillo y de su hermano Francisco, fraile del monasterio de San Isidoro del Campo en Santiponce, refugio de conversos e importante foco de ideas luteranas (Pike, 1968: 879) ${ }^{26}$.

De la familia de Violante Fox pocos datos se nos han conservado. Para Pike no hay duda de que la familia Fox era de artesanos conversos, pero recién llegados a Sevilla, si la comparamos con los Morcillo. Seguramente arribarían a Sevilla como consecuencia de la introducción de la Inquisición en Aragón, Cataluña y Valencia, momento en el que muchos conversos se dispersaron por la península o la abandonaron $^{27}$. Por otro lado, Pike (1968: 879) señala que la madre de Sebastián Fox, Violante de Fox, estaba íntimamente relacionada con los Abrego, también conversos, más concretamente con Antonio de Abrego, marido de su hermana Luisa de Fox, amigo y compañero de gremio de Francisco Morcillo, padre de nuestro autor. A pesar de las dificultades que encontramos para cerciorarnos de los parentescos de Fox Morcillo y sus antepasados, parece clara su ascendencia conversa por su apellido y, como señala Pike (1968: 879), por las dedicatorias de varias de sus obras a la casa de los Niebla y Medina Sidonia, protectores de conversos ${ }^{28}$.

«Sebastián Morcillo» (Tellechea, 2007, tomo 4 (1): 351).

25. "Además de dedicarse a sus respectivos oficios, los Morcillo, como otros artesanos y comerciantes ricos, se aprovecharon de la apertura de las relaciones comerciales entre España y el Nuevo Mundo para incrementar sus fortunas. Concedían préstamos en forma de dinero efectivo y créditos a personas que lo necesitaban para marchar a las Indias. Además, Juan, al igual que Gonzalo, viajó al Nuevo Mundo para vender allí mercancías» (Pike, 1978: 156).

26. Insiste en ello de nuevo Pike (1978: 74).

27. En el año 1487 el rey Fernando el Católico introduce la Inquisición en Aragón, Cataluña y Valencia. Este hecho, como hemos seńalado, produjo el movimiento de muchos conversos, entre los que se encontrarían los Fox, por España o su marcha al extranjero (Pike, 1978: 158).

28. «En Sevilla sobre todo la casa de Medina Sidonia pidió y obtuvo el apoyo de los cristianos nuevos en la lucha contra los Ponce, convirtiéndose finalmente en la gran protectora de aquéllos. 
Esta sería la genealogía de nuestro Sebastián Fox Morcillo, aunque todo su árbol genealógico se encuentra lleno de sombras y relaciones difíciles de confirmar. En un estudio más reciente, Juan Gil Fernández (2000-2003: vol. 4, 492-494) expone de nuevo, aunque entre interrogaciones, que tanto Francisco como Sebastián Fox Morcillo eran hijos de Francisco Morcillo y nietos del sastre ${ }^{29}$ Fernando Morcillo, antes llamado Hernando, e Isabel de Carmona. El único parentesco no mencionado entre interrogaciones en este estudio es el de Sebastián Fox Morcillo y su hermano Francisco, otro de los protagonistas de esta narración.

De la relación de ambos hermanos y de su común afición por el estudio y la erudición humanística, nos han quedado unas pocas muestras. Sabemos que Sebastián Fox Morcillo le dedicó a su hermano su De studii Philosophici ratione, oratio en la que se dirigía a él como destinatario simulado:

Sebastiani Foxii Morzilli de Philosophici Studii ratione ad Franciscum Fratrem Liber. Ego vero mi frater nec tibi longam studiorum rationem, quam alii iustis voluminibus persequuti sunt, in praesentia exponam nec id nunc mei consilii ratio postulat, quae ad Physicen potius docendam, quam ad studii informationem tradendam a me instituitur: sed quae communibus Philosophiae studiis conducere videantur, ea maxime complectar: tu, quod reliquum est, his industriam, atque operam tuam consiliis, et monitis praeceptorum adiutus adhibeto (Fox Morcillo, 1554b: 382) ${ }^{30}$.

Además su hermano — convertido en interlocutor de su diálogo De imitatione (1554) - es presentado como joven instruido, al igual que el propio Sebastián:

In ipso autem sermone hoc, quem duobus libris complecti volumus, Franciscum fratem, in studiis praeclare institutum atque optimae spei uivenem, unaque Ga-

En 1465 por ejemplo, cuando las masas sevillanas se sublevaron contra los conversos, intentando exterminarles y apoderarse de sus riquezas, el duque de Medina Sidonia y sus seguidores se armaron y rechazaron a los atacantes. En los primeros ańos del siglo xvi, la alianza entre los cristianos nuevos y la casa de Medina Sidonia funcionó de forma que fue ventajosa para ambas partes» (Pike, 1978: 44-46). En cuanto a los Niebla es patente su relación con los conversos por la participación de aquellos, junto con los Medina Sidonia, a favor de la casa de los Guzmán en el motín político de 1520. La casa de Guzmán, que dominaba en el Cabildo, no había impedido que los judeo conversos actuaran como Jurados y Caballeros Veinticuatro, dando lugar a un malestar contra los Ponce, apoyados estos por el ducado de Arcos. Incluso, el hermano del duque de Arcos condujo a la plebe, llegando a ocupar el Alcázar. Mientras las autoridades religiosas y civiles se mostraban pasivas, fue la acción de la casa de los Niebla la que logró sofocar la rebelión (Morales Padrón, 1992: 243). 29. Para Gil Fernández (2000-2003: vol. 4, 493) Fernando Morcillo fue sastre y después calcetero.

30. «El libro de Sebastián Fox Morcillo acerca de las razones del estudio filosófico a su hermano Francisco. En verdad, hermano mío, no te expondré por ahora un largo porqué de los estudios, el cual otros expusieron en suficientes volúmenes: no me pide ahora esto la razón, la cual está preparada por mí más para enseñar física que para dar la una idea del estudio; sino que expondré sobre todo estas cosas que parecen conducir a los estudios comunes de filosofía. Tú, por lo demás, ayudándote de estos consejos y advertencias de los que se preocupan por ti, ofrece tu afán y tu trabajo» (Traducción mía). 
brielem Envesiam, amicum ab ineunte pene aetate mihi coniunctissimum, doctum quidem hominem et antiqua generis claritate apud suos insignem, inducimus ( $\mathrm{Pi}-$ neda, 1994: 133$)^{31}$.

Pasados los años, en 1556 aparecerá de nuevo Francisco Fox Morcillo, como personaje de su diálogo De iuventute. Se presentará al trazar el marco dialógico, haciendo coincidir la localización del encuentro ficticio - como he comentadocon un hecho histórico: la llegada de Felipe II para casarse con María Tudor.

Los estudios de ambos hermanos anteriores a su estancia en la Universidad de Lovaina son tan solo vislumbrados a partir de mínimas referencias y diversas conjeturas. En lo que respecta a Sebastián Fox, su etapa de estudios pre-lovaniense, parece deducirse de la necesidad de que un autor, cuya obra In Topica Ciceronis paraphrasis et scholia —editada en $1550^{32}$ —, hubiera estudiado latín antes de su supuesta llegada a Lovaina en 1549 (Espigares, 1994: 224) ${ }^{33}$. Por otro lado, Gon-

31. «En esta discusión, que quiero recoger en dos libros, presento a mi hermano Francisco, instruido con brillantez en sus estudios y joven de óptimas perspectivas, y junto a él, a Gabriel Envesia, amigo muy unido a mí por la edad y sin duda hombre sabio e insigne entre los suyos, por la antigua celebridad de su cuna» (Pineda, 1994: 179).

32. González de la Calle (1903: 40) confesaba no haber localizado esta obra y Espigares (1994: 237 y 2012: 311-313) la da por perdida. El resto de la bibliografía consultada no refiere la localización concreta de ejemplares. Ya Menéndez Pelayo (1982-1991: vol 18, carta no 499: 273-274), en una carta del 24 de agosto de 1905, le pedía a Rodríguez Marín que consultara el ejemplar de In Topica Ciceronis que Bores y Lledó (1884: 273) localizaba en Sevilla. El 29 de agosto de 1905, Rodríguez Marín (Menéndez Pelayo, 1982-1991: vol. 18, carta no 388: 274-280) dice que Bores y Lledó le había dicho por carta que seguramente viera la obra en casa del Duque de T'Serclaes. No obstante, en otra carta datada el 13 de septiembre de 1905, Rodríguez Marín (Menéndez Pelayo, 1982-1991: vol. 18, carta no 499: 283-284) responde que no localizaba ningún ejemplar de la obra en Sevilla y que el propio Bores y Lledó le había confesado que en dicho estudio quería decir que no había localizado ejemplares en Sevilla y que le salió dicho al revés. El carácter general de las valoraciones críticas de Bores y Lledó (1884) no puede asegurarnos que leyera In Topica Ciceronis. En mi inédito Trabajo Fin de Máster Los diálogos hispano-latinos de Sebastián Fox Morcillo: Introducción a su estudio literario y bibliográfico, dirigido por Mercedes Fernández Valladares y defendido en la Facultad de Filología UCM (julio de 2013) di a conocer la existencia de varios ejemplares de la obra In Topica Ciceronis. Localicé un ejemplar en la Biblioteca Nacional de Francia (X-17995) cuya digitalización he recibido. María Casas del Álamo ha localizado, a partir del USTC, no 404159 <http://ustc.ac.uk/index.php/record/404159\#>, otros dos ejemplares de esta obra, uno en la Bodleian Library de Oxford y otro en la Koninklijke Bibliotheek de Bruselas, a la que agradezco muy de veras su solicitud. No he podido localizar el ejemplar sevillano del que habla Bores y Lledó y que Menéndez-Pelayo buscaba. Tal vez se encuentre en alguna de las bibliotecas de los herederos del Duque T'Serclaes de Tilly, pero sus fondos solo resultan hoy accesibles en lo relativo a los impresos menores y las relaciones de sucesos, gracias a la tesis doctoral de Consuelo Gonzalo García (2014). 33. Espigares (1994: 224- 225) dice no entender por qué Vocht data su llegada en 1548 si afirma que Fox Morcillo no es mencionado en ningún documento del colegio. No obstante, como hemos visto, Pineda localizó su nombre en los libros de matrícula, situando su llegada en 1549. González de la Calle (1903: 21) la sitúa también en 1548, diciendo obtener la fecha de conjeturas a partir de las fechas que da en su lista en De iuventute. El problema es que las fechas referidas son de escritura de sus obras, ni siquiera de publicación, y, además, ninguna obra se relaciona exactamente con su llegada a Lovaina (cfr.: Fox Morcillo, 1556: 33). 
zález de la Calle (1903: 19), partiendo de una referencia expuesta en De naturae philosophiae (1554a), en la que Fox se refiere a la visión de un meteoro ígneo, apoya su teoría de que nuestro autor estudió en la Universidad de Alcalá gramática de las lenguas clásicas, pues en España ninguna escuela podía compararse en este momento con la Complutum: «Ac nos etiam aliquando pueri Compluti sub noctem quasi inter pedes discurrentem vidimus» (Fox Morcillo, 1554a: 125) ${ }^{34}$.

Ya Laverde Ruiz, en uno de los primerísimos trabajos dedicados al filósofo sevillano, venía a confirmar los estudios de Fox y de su hermano en la Universidad de Lovaina ${ }^{35}$. Laverde Ruiz afirma que el nombre de ambos personajes aparecía reflejado en los libros de matrícula de dicha universidad en varios cursos, como había comprobado su discípulo y ya íntimo amigo: Marcelino MenéndezPelayo $^{36}$. Más adelante, Henry De Voch determina el año 1548 para la llegada de Fox a Lovaina, junto con Gabriel Envesia ${ }^{37}$. Sin embargo, señala Pineda que en los libros de matrícula de la Universidad de Lovaina solo ha encontrado a Sebastián Fox, matriculado el 1 de julio de 1549, mientras que su hermano Francisco y su amigo Envesia no aparecen en ellos ${ }^{38}$.

Los estudios de Sebastián Fox en la Universidad de Lovaina se reflejan provechosos sin duda en el esplendor que alcanzó su obra. Debió de ser estudiante voraz sin dejar resquicio al ocio entre las páginas de sus libros:

Equidem, ut de me possum ipse iudicare, cum librum sumo legendum, non ante a me dimitto, quam totos in eo dies ac noctes consumpsero, ut totum perlegam demum. Sed nec otiosus esse, aut studiis et cogitationibus uacuus unquam possum, quin aut mecum aliquid, me diter, cogitem, scribam, legam: nullum denique diem, ut aiunt, sine linea intermittam (Fox Morcillo, 1556: 33) ${ }^{39}$.

34. «También nosotros siendo jóvenes lo vimos [el meteorito] en Alcalá durante la noche corriendo casi entre nuestros pies». (Traducción mía).

35. Los estudios de Fox en Lovaina se documentan desde las primeras noticias que tenemos en Escoto (1608: 453). Por supuesto, este hecho dejó un recuerdo literario en el bello campo, que a las afueras de la muralla de la ciudad universitaria de Lovaina, acogía en dulce coloquio a los protagonistas de De imitatione.

36. Laverde (1933: 222) señala que aún Menéndez Pelayo no había publicado su Historia de las ideas estéticas, donde — ciertamente- volvemos a encontrar la afirmación de los estudios de Fox en la Universidad de Lovaina, aunque sin ninguna referencia a la consulta de los supuestos libros de matrícula.

37. «En 1548, dos jóvenes hombres llegaron de España para estudiar en el Trilingüe, Gabriel Enuesia, y su amigo Sebastián Fox Morcillo. Ellos habían sido educados juntos en su infancia en Sevilla, antes de dirigirse a la Universidad brabanzona, donde el segundo se hizo famoso» (de Vocht, 1951-1955: vol. IV, 438).

38. Pineda (1994: 59). En la consulta directa en la Biblioteca Nacional de Francia de los libros de matrícula, editados modernamente, no he hallado más que la referencia a Sebastián Fox Morcillo, el 1 de julio de 1549: «Zebastianus Morchilio, minorennes, [123-125] Hispani.» (Schillings, 1961, vol. IV: 389, no 125).

39. «Ciertamente, en lo que puedo juzgar de mí, cuando tomo un libro no lo suelto hasta que, empleando los días y las noches que necesito, consigo leerlo por completo. No puedo estar ocioso, 
No podemos olvidar, sin embargo, nuestro propósito firme de replantearnos toda la información aportada por la obra de Fox, desde la distancia subjetiva que añade la literatura. Aunque las líneas transcritas, muestra de un estudiante vehemente y desvelado, estén en boca del personaje de Sebastián, se trata de un personaje literario, retratado con la peculiar forma de caracterizar que el género posee. Es decir, evidentemente, el personaje de Sebastián Fox en una apología de la juventud necesita estar fuertemente caracterizado como un joven provechoso, callando — en caso de que existiera - cualquier asueto de la vida estudiantil. No obstante, una simple mirada a la lista de sus obras latinas hace difícil el imaginar que diera demasiada ocasión al ocio ${ }^{40}$. Lo que sí podemos tener por seguro es la sólida formación obtenida por Fox en Lovaina: la oportunidad para convertirse en un humanista de alta talla. Recibió lecciones de latín de Pedro Nannio, de griego de Amerot, de matemáticas y medicina de Gemma Frisio y de filosofía de Cornelio Valerio (Cortijo, 2000: 69). Floreció su mente brillante rodeada de un apasionado ambiente de estudios, que, sin duda alguna, contribuyó a la sin-

siempre me ocupo en mis estudios ó en mis especulaciones; de manera que constantemente, aún á solas, estoy meditando, pensando, escribiendo ó leyendo, pues, no dejo pasar día (como se dice), "sin una línea”" (González de la Calle, 1903: 337-338).

40. La publicación de un primer repertorio tipobibliográfico de la obra del hispalense (Cantarero: 2015 b) me ha llevado a fijar el siguiente corpus de la obra del autor, discrepando en algunos puntos con lo expuesto por Pineda (1994: 63-65) y por otros autores. Refiero tan solo las primeras ediciones de cada una de las obras: (1) In Topica Ciceronis paraphasis: eiusdem scholia in eadem Ciceronis topica, Ex Officina Jan Van de Loe, 1550; (2) In Platonis Timaeum Commentarii, Basilea, Per Ioanem Oporinum, 1554; (3) Compendium Ethices Philosophiae ex Platone, Aristotele, aliisque auctoribus collectum, Basilea, Per Ioannem Oporinum, 1554; (4) De naturae philosophia seu de Platonis et Aristotelis consensioni, Lovaina, Apud Petrum Colonaeum, 1554; (5) De studii philosophici ratione, en De naturae philosohia, Lovaina, Apud Petrum Colonaeum,1554, págs. 165-203); (6) De imitatione seu de informandi styli rationi, Amberes, Excudebat Martinus Nutius, 1554; (7) In Platonis Dialogum qui Phaedo seu de animorum immortalitate inscribitur Sebastiani F. Morzilli Hispalensis Commentarii, Basilea, Per Ioanem Oporinum, 1556; (8) Commentatio in decem Platonis libros de Republica, Basileae, Apud Ioannem Oporinum, 1556; (9) De demonstratione eiusque necessitate ac vi, Basilea, Per Ioanem Oporinum, 1556; (10) De usu et exercitatione Dialecticae, Basilea, Per Ioanem Oporinum, 1556, (11) De honore, Basilea, Per Ioanem Oporinum,1556; (12) De iuventute, Basilea, Per Ioanem Oporinum, 1556; (13) De regni regisque institutione, Amberes, Apud Gerardum Spelmannum sub pomo aureo, 1556; (14) De historiae institutione. Dos ediciones del mismo año: Amberes, Apud Christophorum Plantinum, 1557 y Parisiis, Apud Martinum Iuuenem, 1557. (15) De aquarum generibus, Basilea, Per P. Pernam, 1558 (16) En colaboración con Cornelio Valerio: Physicae sev de naturae philosophia institutio, perspicue et breviter explicata, Antwerpen, Ex Officina Christophe Plantin, 156. La participación de Fox Morcillo en esta última obra se expresa en el propio prólogo, pág. 4. Como se estudia en Cantarero (2015b: 12-14) cuatro de las obras de Fox Morcillo (De demonstratione, De usu et exercitatione Dialecticae, De iuventute y De honore) se publicaron pensando en una doble difusión: en colectánea de las cuatro piezas juntas, por ello existe una portada común para las cuatro obras; o de forma exenta, como se desprende de la fórmula colacional $\left(\mathrm{a}-\mathrm{k}^{8} \mathrm{I}^{4} ; \mathrm{A}-\mathrm{D}^{8} \mathrm{E}^{2} ; \mathrm{aa}-\mathrm{cc}^{8} \mathrm{dd}^{2} ; \mathrm{Aa}-\mathrm{Dd}^{8}\right)$, de la existencia de portadas independientes para tres de las obras (II, III y IV), colofones independientes para cuatro de ellas (I, II y III) y la existencia de numeración de página independiente. 
gularidad de su obra literaria y filosófica ${ }^{41}$. Podemos aún escuchar un lejano eco de los estudiantes que pasearon, sedientos de conocimiento, por las aulas de esta universidad de Lovaina, gracias a la descripción que hizo Calvete de Estrella ${ }^{42}$.

La formación de Francisco Fox Morcillo en la Universidad de Lovaina aparece apoyada, como ya he expuesto, por el testimonio de Laverde Ruiz y por la referencia en De iuventute; sin embargo, Pineda dice no haber encontrado su nombre en los libros de matrícula y en mis comprobaciones tampoco lo he hallado.

Aunque no sea este el lugar para trazar una biografía completa de Francisco Fox Morcillo, debemos señalar los hechos que lo vinculan con los conversos y con el luteranismo, ya que pueden ayudarnos a clarificar, o al menos a sospechar, alguna posible condena por parte de la Inquisición para Sebastián Fox. Sabemos de los primeros estudios de las lenguas clásicas por parte de Francisco Fox, guiado por el maestro Alonso de Medina, gracias a la referencia en De studii: "Quoniam ergo et Latinae, et Graecae linguae mediocriter ab Alonso Metimnaeo viro erudito, praeceptore tuo institutus es " (Fox Morcillo, 1554b: 385-386) ${ }^{43}$.

No obstante, la oratoria no es ajena al artificio literario que reivindicábamos para los diálogos, por lo que debemos ser cautelosos con toda la información que se transmite en De honore y en De studii.

Volvemos a tener una referencia del hermano de nuestro autor, antes de su llegada a Lovaina: participó en las justas poéticas de Sevilla. Según Montoto (1955: XVIII-XIX) se trata de una justa organizada seguramente para el colegio de Santo Tomás, y en casa de un personaje eclesiástico a quien en un dictamen suscrito por el doctor Alonso de Medina y Juan de Quirós dan tratamiento de magnífico. Monto-

41. La Universidad de Lovaina fue fundada en 1425 por el Duque Juan de la casa de Borgońa. El privilegio le fue concedido por el Papa Martino V. En 1517 se fundó el colegio trilingüe por Jerónimo Busleiden. Es el siglo xvi el momento de máximo esplendor para la Universidad de Lovaina. Fueron frecuentes las excursiones científicas y la imprenta de la ciudad propició una gran revolución en la transmisión del conocimiento científico y humanístico. González de la Calle (1903: 309-312) traza un breve bosquejo de esta Universidad partiendo de lo expuesto por el testimonio de Juan Christóbal Calvete y de Charles Bulens (1900).

42. «Ay en Lovayna el collegio de los Theólogos y el Trilingüe, y otros muchos sin estos, en los quales y en las escuelas se leen y exercitan las lenguas Latina, Griega y Hebrayca, artes liberales, philosophia, medicina, leyes, cánones, theología. Ay professores en todas las facultades, entre los quales es uno de los más celebrados Rovardo de Enchusia, deán y chanciller de aquella Universidad, profundissimo theólogo, y Pedro Curcio, theólogo; Gabriel, jurisconsulto; Gemma Frisio, singular médico y mathemático, Pedro Nannio, Profesor de las letras griegas y Latinas, y otros. Por toda la villa se habla mucho latín, aun en las casas de los oficiales, de manera que ellos y algunas muxeres lo entienden» (Calvete de Estrella, 2001: 168).

43. "Puesto que tú has sido preparado con sencillez en la lengua griega y latina por tu preceptor Alonso de Medina, un hombre erudito». (Traducción mía). Del maestro de Fox podemos referir la siguiente información: «Fray Alonso de Medina, Religioso Profeso de la Órden de San Francisco en la casa grande de Sevilla, Veinticuatro y Tesorero que fue de esta ciudad, varón de singular virtud y fama de santidad, que murió con opinión de venerable, y se enterró en la Capilla de los Burgaleses de su Convento... » (Matute y Gaviria, 1886: tomo I, p. 25). 
to data estas justas en octubre de 1549 . Además, enumera los veinte temas religiosos propuestos, de entre los cuales el último, «A la Santísima Cruz», sería al que dedicó su poema el hermano de Sebastián Fox, que aparece como «Francisco Sebastián de Fox». ${ }^{44}$ Sin embargo, en una publicación más reciente Juan Gil Fernández (2004: 253-255) edita el poema del que considera con total seguridad hermano de Fox Morcillo: «Francisco Morcillo de Fox». El poema, titulado «In laudem sanctissime crucis epigramma», se contiene en un códice facticio de la Biblioteca Capitular de Sevilla con signatura Ms. 59-6-14 (olim Ms. 64-7-90). Respecto a la fecha de composición de estas creaciones dice Juan Gil «Nada sabemos del año en que se celebraron estas justas, salvo que una de ellas, la dedicada a Santo Domingo, tuvo lugar en setiembre de 1549 (f. 118r).»(Gil Fernández, 2004: 254).

En 1545 encontramos a Francisco matriculado en el Colegio de San Ildefonso, de Alcalá de Henares y, en el de San Antonio de Portaceli, de Sigüenza (Espigares, 1994: 225). En cuanto a la llegada a Lovaina de Francisco Morcillo se sitúa, por la referencia temporal ya comentada del marco dialógico en De iuventute, en 1554. En esta universidad — como especifica De Vocht (1951-1955: tomo IV, 440) - se dedicaría al estudio del derecho y, a la vuelta a España, profesará en los jerónimos.

A estos mínimos retazos de su biografía les sigue el silencio impuesto por la sospecha. A partir de este momento perdemos las referencias de Francisco Morcillo y toda la información que podemos relacionar con su persona aparece atribuida a un jerónimo con el apellido de Morcillo. Menéndez Pelayo no identifica al hermano de Fox con el fraile jerónimo Francisco Morcillo de San Isidoro que aparece como «relajado en persona» por luterano en el Auto de fe que tuvo lugar el domingo 24 de septiembre de 1559 en Sevilla, donde fueron quemadas veintitrés personas ${ }^{45}$. Sin embargo, de este «P. Morcillo» dice Menéndez Pelayo (1982: 267) que abjuró en el último momento evitando la muerte en la hoguera. Esta supuesta abjuración se contradice con las palabras que encontramos en un sorprendente y conmovedor testimonio de época, en Santae Inquisitionis Hispanicae artes..., Heidelbergae, 1567:

Etiam in illo arctissimo carcere usus est Deus ipsius ministerio ad erigendum Morzillium quendam iuvenem monachum ex coenobio Divi Isidori ob libe-

44. Pineda (1994: 56) cita también la asistencia de Francisco Fox a esta justa, a partir de la referencia de Santiago Montoto: «El ambiente de Sevilla era propicio para estas justas, pues no fueron solamente las patrocinadas por el Obispo de las Escalas las que se celebraron en la primera mitad del siglo Xvi. Entre otras, puede señalarse por su interés, dado el número de poetas que a ella concurrieron, la del mes de octubre de 1549, probablemente en casa de un personaje eclesiástico, a quien en un dictamen suscrito por el doctor Alonso de Medina y Juan de Quirós dan tratamiento de magnífico» (Montoto, 1955: XVIII). Los nombres de los participantes en esta justa con el tema Xx —entre los que se encuentra Sebastián Morcillo de Fox— se pueden ver en las págs. XXII-XXIII. 45. Se trata de una información expuesta por Gil Fernández (2000-2003: vol. 4, 492-494) y extraída del Archivo Provincial de Sevilla, V. 1557, 3 (=3396), página descabalada. 
riorem Evangelii confessionem eo petractum: qui dimotus pollicitationibus ac blandis promissis Inquisitorum a pia confessione paulo ante desciverat. Dei consilio, qui Morzillium sane in Christo amabat, factum est, ut hunc Ferdinandum eo tempore Inquisitores carceris illi comitem darent, qui, intellecta iuvenis vecordia, eum acerbe obiurgat, accusat defectionis coram Christi tribunali, facit resipiscere, erigit, consolatur, confirmat. Paucis postea diebus Morzillius audientiam petit, in qua coram dominis sollemniter eiurat retractationem paulo ante a se factam atque eam sibi fidei confessionem constare postulat, quam ediderat primum quamque pro Christiana haberet. Combustus hic fuit in hoc eodem actu mortuus, an sub Inquisitoria rursus an sub Dei misericordia nescitur (Castrillo, 1991: 386) ${ }^{46}$.

El papel de Fernando de San Juan es, pues, fundamental para convencer a fray Morcillo de no venirse abajo y defender sus convicciones ante el tribunal inquisitorial, olvidando incluso el temor a la muerte. Méndez Bejarano había hablado de cómo Morcillo, al que identifica con Francisco Morcillo Fox - partiendo de Skinner (1569: Fol. Ddiii. v)—, se había retractado en la cárcel de su abjuración ${ }^{47}$. Es Vicente Skinner uno de los primeros en establecer la identificación de este Morcillo ajusticiado con el hermano de Fox, en el registro que añade al final de su traducción de Santae Inquisitionis Hispanicae artes sobre los ajusticiados en Sevilla $1559^{48}$. Guillén (1963: 82), quien también corrige a

46. «También se valió Dios de su ministerio para alentar en aquella angostísima cárcel a cierto joven llamado Morcillo, fraile del Convento de San Isidoro, que se había visto arrastrado allí por su sincera confesión del Evangelio y que al poco tiempo, movido por los ofrecimientos y blandas promesas de los Inquisidores había desertado de su piadosa confesión. Pero la Providencia de Dios, que ciertamente amaba a Morcillo en Cristo, quiso que por aquel tiempo los Inquisidores le dieran por compańero de cárcel a este Fernando, el cual, sabida la pusilanimidad del joven, lo reprende duramente, le reprocha su defección ante el tribunal de Cristo, lo hace recapacitar, lo levanta, lo consuela, lo hace fuerte. Pocos días después, pide Morcillo una audiencia, en la que abjura solemnemente delante de los señores la retracción de lo que había dicho poco antes y pide conste la confesión de fe que había hecho al principio y que tenía por cristiana. Quemaron a este en el mismo Auto de fe, después de muerto, no se sabe si por una nueva gracia de los Inquisidores o por la misericordia de Dios» (Castrillo, 1991: 387).

47. Méndez Berjarano (1922: tomo I, 213-214) no explica de dónde obtiene el informe de la decisión de Francisco Morcillo para retirar su abjuración. Parece ser, sin embargo — por citar más adelante la obra Sanctae Inquisitionis Hispanicae artes aliquod detectae, ac palam traductae, Heidelberg, 1567, en la traducción de Skinner- que sea esta la fuente.

48. Como estudia Ames (1819, vol. IV: 110-111) y reitera Castrillo (1991: 93-94), esta segunda traducción de Santae Inquisitionis Hispanicae artes aliquod detectae, ac palam traductae..., llevada a cabo en 1569 por Vicente Skinner y titulada A discouery and playne declaration of sundry subtill practises of the Holy Inquisition of Spayne, corrige errores de la primera traducción al inglés de 1568 y añade un registro de aquellas personas que fueron quemadas en Sevilla en 1559, 1560 y 1563 y en Valladolid 1559. En dicha lista se aclara: «Francisco Foxio Morzillo, a Monke of S. Isidors cloyster in Siuil brother to Sebastiano Foxio Morzillo, the late writer in Philosophy. Of this Morzillo mention is made, Folio. 71» (Skinner, 1569: Fol. Ddiii. v.). El ejemplar que consulto en la Biblioteca Nacional de España, con signatura U-8803, presenta erratas en numeración, por lo que la información referente a Fox Morcillo se encuentra en la hoja con sign. Tiiij v,. correspondiente al 
Menéndez Pelayo en lo que respecta a la muerte de Francisco Morcillo, no esclarece tampoco el episodio acaecido y narrado en Santae Inquisitionis Hispanicae artes. Parece verosímil, por lo tanto, basándonos en los dos testimonios de época y apoyándonos en los trabajos de Pike (1968) y Gil Fernández (2000-2003), que el fraile jerónimo del monasterio de San Isidoro del Campo, quemado por luterano en el Auto de fe de 1559, fuera Francisco Morcillo Fox, hermano de nuestro autor.

Mientras el paradero de Francisco parece esclarecerse a la luz de su identificación con el personaje del padre Morcillo, el de su hermano se nos presenta sumamente misterioso. El intentar dar sentido al conjunto de retazos conservados sobre el final de la vida de Fox Morcillo constituye un procedimiento que casi podríamos calificar de policíaco. La mayoría de fuentes biográficas hablan de la muerte del filósofo español como fruto de un naufragio. La primera noticia que tenemos de este hecho, se debe a dos mínimas referencias insertas en dos cartas de Hubert Languet ${ }^{49}$. Las dos se contienen en Arcana Seculi decimi sexti Humberto Langueti legati, dum viveret, et consiliarii saxonicii. Epistolae secretae ad principem suum Agustum...

La primera de ellas es la número xvi, dirigida a Philippo Melanchthon y datada seis días antes de los Idus de abril (8 de abril) de 1560, en Francofordia (Frankfurt):

In Hispania innumeri interficiuntur propter religionem. Recens in solo Cataloniae comitatu, ad duo aut tria millia hominum fuerunt coniecta in vincula. Falsum est quod audiveramus de Archiepiscopo Toletano affecto suspicio, vivit adhuc et est suplicio eum non fore constantem. Foxius Mirzillus Hispanus insigniter doctus fugiens incendium periit naufragio (Languetus, 1699: libro II, 40-42) ${ }^{50}$.

Fol. 71v. [=72 v.]. La digitalización de dicho ejemplar está disponible en la Biblioteca Digital Hispánica, <http://catalogo.bne.es/uhtbin/cgisirsi/Jyim6cQlph/BNMADRID/161270222/2/33>.

49. Pineda (1994: 47) habla de una sola carta, epístola XviII, cuya fecha y destinatario (Philip Melanchthon por Hubert Languet a 10 de abril de 1560) no coinciden con el destinatario (Ulricho Mordisio) ni con la fecha (10 de abril de 1550) que constato en los dos ejemplares que he podido consultar del epistolario a partir de digitalización: ESTADOS UNIDOS, Princeton University Library, Goertz 7953, Accesible on-line en: <http://babel.hathitrust.org/cgi/pt?id=njp .32101078438841 ;view=1 up;seq=1>; MUNICH, Bayerische Staatsbibliothek, 4 Epist. 103 ha-2, Accesible on-line en: <http://books.google.es/books?id=jJFBAAAAcAAJ\&pg=RA2PA41\&lpg=R A2PA $41 \& \mathrm{dq}=$ fugiens+incendium + periit + naufragio\&source $=$ bl\&ots $=$ WoNpXuKLAZ\&sig=NY JfHMAUWitnsxPHuN41GpywNjA\&hl=es\&sa=X\&ei=RjYCU4aTOKTt0gXWhoDYBg\&red ir_esc $=\mathrm{y} \# \mathrm{v}=$ onepage $\& \mathrm{q}=$ fugiens $\% 20$ incendium $\% 20$ periit $\% 20$ naufragio\&f $=$ true $>$. No obstante, el texto transcrito por Pineda (1994: 47) coincide exactamente con el que cotejo en los dos ejemplares referidos.

50. «En Hispania muchos son condenados a muerte a causa de la religión. Recientemente solo en el condado de Cataluña dos o tres mil hombres fueron conducidos a la cárcel. Es falso lo que habíamos escuchado del tormento padecido por el arzobispo de Toledo, vive todavía y existe la sospecha de que él no se mantuvo inquebrantable. Fox Morcillo, un hispano extraordinariamente sabio, murió en un naufragio huyendo de la hoguera» (traducción mía). 
La segunda de las cartas es la número XviII, dirigida a Ulricho Mordisio y datada el 10 de abril de 1550, en Francofordia (Frankfurt).

In Hispania innumeri interficiuntur et coiiciuntur in carceres. In solo Cataloniae Comitatu capta sunt duo aut tria millia hominum religionis causa. Toletanus Archi-Episcopus non est affectus supplicio, et suspicio est eum non fore constantem, Foxius Morzillus Hispanorum ut existimo doctissimus, fugiens incendium periit naufragio (Languetus, 1699: libro II, 45-47) ${ }^{51}$.

Estas referencias, la de la carta XVI —solo citada por Lueben (1914: 1)—y la incluida en la XVIII — recuperada ya por varios estudios ${ }^{52}$ - son los primeros testimonios que poseemos sobre la relación de la muerte de Fox con un naufragio. Ahora bien, para Kuiper (1941: 201, nota 1), el que se piense que Fox Morcillo huía de la inquisición cuando su barco naufragó, pudo deberse a una mezcla del paradero de Sebastián Fox con el de su hermano. Sin embargo, esta referencia vuelve a aparecer, años más tarde, en el texto de Escoto:

Igitur evocatus honoris gratia in Hispaniam, procerum suasu a Philippo II Hispaniarum Rege vt Caroli filii regnorum heredis, studiis praesset, navem ubi conscendit, orta in Oceano ingenti tempestate, naufragio, et in aetatis, heu, flore, periisse fertur... (Escoto, 1608: 453-454) ${ }^{53}$.

51. «En Hispania muchos son condenados a muerte o son confinados en cárceles. Solo en el condado de Cataluña son apresados dos o tres mil hombres por su religión. El arzobispo de Toledo no se vio afectado por el tormento y existe la sospecha de que él no fuera firme, Fox Morcillo, el más sabio de los hispanos, según creo, huyendo de la hoguera murió en un naufragio» (Traducción mía). 52. Hay que tener en cuenta que, si seguimos los ejemplares consultados y ya referidos del epistolario de Languet, tanto Pineda (1994: 47) como Kuiper (1941: 201) confunden el año (1550) y el destinatario (Urdicho) de la carta que citan (XviII) con el ańo (1560) y el destinatario (Melanchthon) de la epístola xvi que no mencionan. Tal vez la falta de referencia a la carta xvi sea debida a que no consta en el índice onomástico que encabeza el epistolario de Hubert Languet (1699: 6). Lueben (1914: 1) cita la epístola Xvi con Melanchthon como destinatario, aunque está claro que transcribe la carta Xvi por contener lo que él considera una variante del apellido del hispalense «Mirzillus» — tal vez una errata — que no figura en el texto de la epístola XviII. No obstante, cuando Lueben (1914: 2) refiere la muerte de Fox, la sitúa en 1560, año que no coincide con la fecha que — como he dichocotejo en las digitalizaciones que he podido localizar del epistolario de Languetus (1550).

53. «Así pues, convocado a España por el rey de los españoles, Felipe II, aconsejado por los aristócratas, debido a su fama, para que se pusiera al frente de los estudios del heredero de sus reinos, su hijo Carlos, se dice que cuando subió a la nave, habiendo surgido una tempestad en el gran océano, murió en un naufragio, ¡ay!, en la flor de la edad». (Traducción mía). Los siguientes dísticos elegíacos a modo de epitafio: «Ante diem quid me raptum lugetis amici? | Fallor? an ingenium docta per ora volat? | Caelo animam condis, doctis tua scripta Sebasti[ane]. I Committis, corpus quis tenet? Oceanus. | Spiritus astra tenet, | Morsilli scripta diserti | Tellus: corpus ubi est? heu, rapit Oceanus» (Escoto, 1608: 454). "¿Por qué me lloráis a mí, oh amigos, arrebatado antes de tiempo? ¿Me equivoco? ¿O es el ingenio el que vuela a través de vuestras sabias bocas? Escondes tu alma en el cielo, Sebastián, pero entregas tus escritos a los sabios. ¿Quién tiene tu cuerpo? El océano. Los astros tienen tu espíritu, la tierra los escritos del prolífico Morcillo. ¿Dónde está tu cuerpo? ¡Ah!, se lo lleva el océano.» (Traducción mía). 
En la referencia de Escoto podemos ver que el naufragio se sitúa en su viaje de vuelta a Espańa, al ser llamado por Felipe II para ser preceptor de su hijo Carlos. Es decir, no se nos dice que existiera ninguna relación entre su marcha y la persecución que pudo sufrir por la Inquisición. El texto de Escoto fue el más difundido, por lo que la mayoría de referencias a Fox se atienen a esta muerte en un naufragio cuando volvía a España, desvinculándola del supuesto fuego inquisidor ${ }^{54}$.

Gracias a un documento recuperado por los Avisos de la Real Biblioteca (Real Biblioteca, 2005) sabemos que el filósofo español llegó de vuelta a Sevilla sano y salvo en torno a 1556, para concertar la hacienda de sus hermanos, plural por el que suponemos que tuvo más de un hermano, aunque el conocido para nosotros sea Francisco ${ }^{55}$. Se trata de una carta extraída del epistolario del cardenal Granvela. En ella el hispalense se dirige a él, como ministro poderoso y gran mecenas de las letras, para hacerle llegar un ejemplar de su obra: Commentario in decem Platonis libros de Republica. Al tiempo le informa de la mala situación del país y de su intención de volver a Bélgica, pensemos que Granvela se encuentra en Flandes en aquel momento. Nos informa también de un interés de Fox hasta ahora desconocido, pero nada extraño para la época: las antigüedades. $\mathrm{Al}$ parecer, Fox Morcillo recopila restos arqueológicos y monedas para el cardenal. Cierra la carta diciendo a este que sabe que el rey busca cronista y le pide su intervención para favorecerle en dicho puesto:

Muy ilustre y Reverendísimo Señor, yo llegué a Seuilla bueno en muy breve, donde agora estoy concertando la hazienda de mis hermanos, que tenían necesidad harta dello. Allá encomendé a cierto amigo diese a vuestra señoría el comentario sobre la República de Platón. Vuestra señoría rreciba el seruicio, o por mejor decir, la uoluntad de quien desea seruir en más que en esto. Yo ando acá buscando antiguallas para vuestra señoría. En Cáliz hallé rrastros de un templo de figura oual de 80 pies en ancho y 200 en largo. Algunas piedras se hallan, y monedas, que aunque sean para vuestra señoría muy viexas no dexaré de coger, y ni más ni menos haré en todas las partes do estuuiere. De allá me han avisado que Su Magestad quiere proueer la crónica: suplico a vuestra señoría, si ay en mí méritos para ello, no dexe de fauorecerme de este nego$\operatorname{cio}^{56}$. Yo daré la buelta allá muy presto si la uenida de Su Magestad no es tan presto. La tierra está carísima y muy pobre. Yo quedo bueno rrogando a Dios por la muy ilustre y reverendísima persona de vuestra señoría. De Seuilla, a 21 de nouiembre de 1556. Vesa las manos de vuestra señoría, el maestro Sebastián Fox Morcillo.

54. Repiten la historia, entre otros: Baillet (1688: 140), Nicolás Antonio (1783-1788: vol. II, 280), Arana de Varflora (1791: 92), Laverde Ruiz (1933: 240), González de la Calle (1903: 24) y Méndez Berjarano (1922: 214).

55. La carta ha sido comentada también en la puesta al día de la biografía de Fox que se hace en Espigares (2009: 800-801).

56. En su obra De historiae institutione, Anturpiae, Apud Christophorum Plantinum, 1557, Fox Morcillo presentaba su noción de la historia, lo que seguramente se relaciona con este deseo de convertirse en cronista real. 
Por otro lado, fue en 1923 cuando Rodríguez Marín presentó la primera prueba documental - y única en aquel momento- de la vida de Fox. Se trata de la noticia de la cédula de empeño de unos libros a favor de Arias Montano. En la noticia se indica que la cédula referida iría firmada por Fox Morcillo:

Sevilla, 7 de diciembre de 1558.

En cierto inventario que se hizo el 4 de septiembre de 1598 de algunos de los bienes quedados por la muerte de Arias Montano, figura: «Vn memorial de libros latinos y griegos y otros diuersos y al fin del una çedula de empeño de ellos, fecho y firmado del maestro Sebastián fox morçillo al doctor Arias Montano en seuilla a siete de diziembre de 1558 por seis mil marauedis» (Archivo de protocolos de Sevilla, oficio 3º, Gaspar Reyes, libro $3^{\circ}$. de 1598 , fol. 160) ${ }^{57}$.

La noticia de la cédula pertenece al tercer inventario de bienes de Arias Montano, datado en Sevilla el 4 de septiembre de 1598. Este documento no solo nos facilita el destino de algunos de sus libros, sino que se opone a muchas de las referencias de época que hemos venido recogiendo, confirman su llegada de Lovaina y nos llevan a una nueva conclusión: Sebastián Fox Morcillo seguía vivo en 1558, cuando firmó aquella cédula en Sevilla.

De tal manera que tan solo la epístola $\mathrm{XVI}^{58}$, datada en 1560 , podría no contradecirse con la prueba documental de la cédula. Quedaría, por tanto, fuera de lugar el seguir pensando que Fox naufraga en el viaje de regreso a su patria, como se ha repetido en muchas ocasiones, siguiendo el testimonio de Escoto.

Llegados a este punto, debemos preguntarnos el porqué de la persecución inquisitorial que parece referir la carta de Languet. A la luz de sus textos no parece existir ninguna opinión que pueda transgredir la ortodoxia; sin embargo, un documento conservado en la Real Academia de la Historia, el Proceso de Carranza, desvela los temores que pudo haber sufrido el filósofo español, y que le habían podido impulsar a huir de España, una vez que había regresado de Lovaina ${ }^{59}$. Antes de introducirnos en las palabras de dicho documento, debemos reparar en ciertos aspectos del clima heterodoxo que parecía estarse desarrollando en Lovaina en aquellos años. Para ello nada mejor que partir del estimulante trabajo de Ignacio Tellechea Idígoras (2000: 132-155), que resumo a continuación, donde revisa estos apasionados años de enfrentamientos religiosos, persecuciones y reuniones clandestinas de estudiantes.

En 1557, con todos los poderes en manos de Felipe II y con su padre retirado al monasterio de Yuste, nos encontramos con un clima de escisión, de contienda funesta entre católicos y protestantes. La Universidad de Lovaina no recibía estos

57. Este documento aparece editado por Rodríguez Marín (1923: 64) y posteriormente vuelve a aparecer en Rodríguez-Moñino (I928: 597).

58. No hay que olvidar que Pineda confunde el número de la epístola por el xvirII.

59. Proceso de Carranza, XI, 350-60. 
aires de cambio y de oposición religiosa por primera vez, sino que ya en 1519, antes incluso de la condena de Lutero, se había visto obligada a reprobar ciertos planteamientos luteranos. El dominico Fray Bartolomé Carranza, justo antes de trasladarse a Toledo para ocupar el arzobispado, pasó unos meses en Bruselas, donde dio la alerta del ambiente heterodoxo que se vivía en aquella ciudad. Esta situación, de la que informó primero al decano de la Universidad de Lovaina, Ruard Tapper y, posteriormente al propio Felipe II, podría resumirse en la existenci a de un núcleo de fugitivos sevillanos en Flandes, que enviaban obras protestantes a Espańa; la ignorancia del clero, que permitía que los calvinistas hablaran sin censura y, lo que más nos interesa: el sospechoso ambiente alejado de la ortodoxia católica de los estudiantes de Lovaina. Estas informaciones desencadenaron una serie de actuaciones contrarreformistas ${ }^{60}$, entre la que se sitúa la del dominico Fray Baltasar Pérez en Lovaina. La información le fue dada a este enviado por el padre de Francisco de Ayala, uno de los estudiantes de Lovaina, y por el impresor Juan Bellero, quien le desveló la vía de entrada en Amberes de los libros protestantes procedentes de la feria de Francfort. Eran los fugitivos españoles los que los llevaban a los libreros de Amberes, sin dejar de pasar por Bruselas y Lovaina, existiendo en Castilla y Aragón quienes pagaban las caras ediciones ${ }^{61}$.

Pero arribando ya al punto verdaderamente central de este análisis, el propio Baltasar Pérez, no solo informó de palabra a Carranza, sino que declaró por escrito ante la Inquisición de Sevilla en 1558, con la información de su etapa de estudios en Lovaina. El testimonio ha sido estudiado por Tellechea (1963: 21-33) en un trabajo anterior al ya citado. En primer lugar, en el informe da cuenta de la figura de Miguel Bayo en Lovaina, el interés que suscitó entre el alumnado defensor, a pesar de la condena de Pío V; y la preocupación de algunos por la heterodoxia ${ }^{62}$

60. Ante las declaraciones de Carranza, Felipe II en persona se interesó en clarificar la situación, ordenando una investigación pormenorizada. Se confirmó la venta de libros luteranos a las puertas del palacio real en Bruselas, se expulsó a dos dominicos (Fray Diego de Ortega y fray Julián de Tudela) y se convocó una reunión del Consejo de Flandes a la que asistió el propio decano de Lovaina. De esta indagación se llegó a la detección de obras protestantes de Ginebra en la imprenta de Jean Crespin. En el contexto de esta investigación se llegó a enviar de incógnito al agustino Villavivencio, para que en la feria de libros de Francfort, reconociera a quienes compraran las obras filoluteranas (Tellechea, 2000: 138).

61. Tellechea (2000: 138-139).

62. Miguel Bayo (1513, Melin, Bélgica-1589, Lovaina) fue profesor en la Universidad de Lovaina y en 1549 inició su enseñanza de ciertas ideas heterodoxas, denunciadas ante el claustro de la Universidad de París, que en 1560 reprobó ciertas tesis bayanistas. La teología de Miguel Bayo parte del análisis de dos estados opuestos: el del hombre antes del pecado original de Adán y la humanidad redimida por Cristo. Para Bayo el estado de gracia primigenio, en el que vivía el hombre antes del pecado de Adán, era exigencia de la naturaleza humana y no un don gratuito de Dios. Este principio hacía que el estado de naturaleza caída privara al hombre no solo de dones de tipo sobrenatural, sino también naturales. De tal manera que considera pecados todos los actos de los no reconciliados. No obstante, Bayo sí consideraba la existencia de cierto grado de gratuidad en el estado primigenio, pues el ser humano había alcanzado aquel estado sin méritos propios. El pro- 
y peligrosidad de su doctrina ${ }^{63}$. A raíz de esta situación un grupo de estudiantes, entre los que se encuentra Sebastián Fox Morcillo, se reunían en casa de un tal Pedro Ximénez ${ }^{64}$, que había constituido su propia escuela en la que contravenía por la tarde las lecciones dictadas por la mañana en la Universidad ${ }^{65}$. Este grupo estuvo formado por un gran número de heterodoxos, más o menos temerosos, entre los que se encontraban: Agustín Cabeza de Vaca, Fray Lorenzo Villavicencio, Sebastián Fox Morcillo, el futuro jesuita Ledesma, Pedro de Ortega y el primer detractor del grupo y delator de todos ellos: fray Baltasar. Más adelante se sumaron Felipe de la Torre y un soldado aficionado a latines. Se añadirían aún a esta nómina otros dos recién llegados de Salamanca: Grajal y Maldonado; junto al agustino Fray Cristóbal de Sanctotis ${ }^{66}$.

Sin más dilación escuchemos las palabras de fray Baltasar sobre el filósofo sevillano que, como ya hemos señalado, declara ante la Inquisición en Sevilla el 26 de mayo de 1558 :

De este Sebastián Morcillo, que reside aquí en esta ciudad, por la comunicación que tenía con estos, se tuvo allá gran sospecha; porque, habiéndole hecho el Rey Maestro de sus pajes, estando ya en su oficio, salió aquel libro que he dicho de aquel Ceriolario. Por amor de aquel, comenzaron a recatarse en la Corte de todos los que estuvieron en Lovaina, y envió don Antonio de Toledo, caballerizo mayor de Su Majestad, un capellán de los pajes para que preguntase y se informase de la doctrina del dicho Morcillo. Y trujo señaladas ciertas personas a quien había de preguntar. Y díjome a mí un doctor Joverio, a quien él venía enderezado, que me había de hablar,

blema esencial radicaba en la consideración de que un hombre reconciliado, al igual que en el estado primero, recuperaba la capacidad de obrar bien, mientras que a un hombre no reconciliado se le impedía cualquier acto bueno natural. Esta consideración hacía que se acercara a las herejías maniqueas, como el luteranismo, pensando que un hombre sin la gracia no tenía libertad interior, no podía obrar bien en ninguno de sus actos ni resistir a las tentaciones: todo era pecado. La primera obra de Miguel Bayo, De libero hominis arbitrio eiusque potestate, fue publicada junto a De iustitia et iustificatione en 1563. Su asistencia al Concilio de Trento en su última etapa no impidió que se reafirmara en todas sus posturas. Ya en 1564 publicaría De merito operum, De sacramentis in genere contra Calvinum y un De verbis sine quibus non perficitur sacramentum Baptismi (Illanes y Saranyana, 1995: 145-147).

63. Las Universidades de Salamanca y Alcalá procedieron a censurarlo en 1566, después de que el propio Felipe II les pidiera que se examinara su doctrina. En 1566 Bayo editaría De libero arbitrio y De peccato originis, que dieron lugar a que finalmente, en 1567 , se proscribiera su doctrina con la publicación de Ex omnibus afflictionibus, condenando sesenta y nueve de las proposiciones defendidas por Miguel Bayo (Illanes y Saranyana, 1995: 145-147).

64. Tellechea se pregunta por la identidad de este Pedro Jiménez/Ximénez, jefe del grupo bayanista: « $i$ El secretario de Diego Hurtado de Mendoza que desaparece a raíz de la desgracia política de su amo?, De Vocht menciona un Petrus Ximenus que vivió algún tiempo en Padua con Vesalius, fue profesor de Medicina y editó un Dialogus de re medica (Valencia 1549). En la declaración de Fray Baltasar es calificado de «buen latino y griego y hebreo y filósofo», lo que acaso puede conciliarse con su profesión de Medicina. ¿O será un Pedro Ximénez que más tarde publica en Alemania una obra con intenciones irenistas?», Tellechea (2000: 140).

65. Tellechea (2000: 140-141) y Tellechea (1963: 22-23).

66. Tellechea (1963: 24-25). 
y informarse de lo que yo sabía de él. Yo le dije a aquel doctor, que dijese al capellán que no me hablase a mí, porque negocios de aquella calidad, no se habían de decir a don Antonio ni a otro clérigo particular; que si querían algo, que enviasen allí un inquisidor, y entonces cada uno descargaría su conciencia. [...] Yo no sé si otros le informaron de algo; que dentro de breve tiempo se vino el dicho Sebastián Morcillo a España con nombre de que tray cinco meses de licencia y nunca más ha vuelto allá (Tellechea, 2007, tomo 4 (1): 351).

Son muchas las conclusiones a las que nos llevan estas palabras. En primer lugar debemos señalar que se confirma la teoría de la elección significativa de los nombres expuesta por Pike, pues vemos que solo se le llama por su apellido paterno Morcillo $^{67}$. En segundo lugar, y atendiendo ya más propiamente a las cuestiones que nos ocupan, sabemos que Sebastián Morcillo reside en Sevilla en 1558, ratificándose los datos de la cédula de los libros cedidos a Arias Montano. En tercer lugar, se nos aporta un dato que se opone de nuevo a lo transmitido ya por Escoto: Sebastián Morcillo no había sido llamado a ser preceptor del príncipe Carlos en 1556, sino maestro de pajes ${ }^{68}$. Aunque el príncipe no fuera su discípulo directo, sí participaría en el proyecto educativo del infante, pues, ilustrando a estos nobles acompañantes, proporcionaría para el hijo de Felipe II un ambiente humanístico y de alto nivel intelectual. No podemos olvidar que en

67. Pike (1968: 877-881).

68. Espigares (1994: 230) repara en ello, sin embargo no explica el papel y la importancia de este maestro de pajes. Como expone Gonzalo Sánchez-Molero (2013: 69-72), la búsqueda de modelos para la educación del príncipe Felipe tuvo en cuenta la llamada escuela de pajes, creada en 1492 por la reina Isabel, para dotar de educación literaria a los jóvenes nobles residentes en la corte. El mismo José Luis Gonzalo repasa la historia de esta institución en la que creo que debemos reparar. Fue Pedro Mártir de Anghiera el elegido para ocupar el puesto por primera vez y para constituir lo que consideró una academia para los nobles españoles al estilo de Sócrates y Platón. Jerónimo Münzer asistió a las lecciones del humanista, comprobando cómo los jóvenes recitaban a los autores clásicos. Las lecciones incluían enseñanzas en civilidad, artes liberales, ejercicios físicos, etiqueta cortesana, ajedrez y latín. El segundo maestro de pajes, Lucio Marineo Sículo (1499), escribió su Gramatica brevis ac perutile para sus alumnos, que más adelante se volvería a emplear para la educación de Felipe II. En 1504 Isabel ordenó el pago de 30.000 maravedíes a Pedro Mártir de Anghiera como capellán y maestro de los caballeros de la Corte en artes liberales. A pesar de ello, Sículo siguió hasta la muerte de la reina Isabel, cuando sus clases cesaron por un período de cuatro años. Pasado ese tiempo Fernando el Católico convoca de nuevo a Pedro Mártir de Anghiera para que prosiguiera en su cargo, ahora firmado por la reina Juana como maestro de los caballeros en las artes liberales. Fue Cisneros en 1516, con la muerte de Fernando el Católico, quien suspendió el sueldo del humanista. A pesar del intento de recuperar al maestro de los caballeros de corte por Carlos V en 1520, su ausencia y las guerras de las comunidades imposibilitaron la continuación de esta empresa humanística. Finalmente en 1530, por la querencia de crear una Casa al estilo de Castilla para la emperatriz Isabel, se restituye el cargo de maestro de gramática de los pajes, que simplemente por el título se veía desprestigiado. Bernabé del Busto sustituirá a Anghiera en esta escuela de gramática, acompañado de un repetidor, tal vez Juan Bravo, escuela de gramática que murió con la Emperatriz en 1539. Juan de Zúńiga instó a Carlos V a recuperarla en 1540, para poder educar a los más jóvenes pajes de Felipe II. Fue Juan Cristóbal Calvete de Estrella quien se ocupó del cargo hasta 1556, cuando se encomendó el puesto a Sebastián Fox Morcillo. 
1556 publica en Amberes De regni regisque institutione libri III, largo diálogo que elogiaba la institución de la monarquía y la figura de Felipe II en concreto, por lo que seguramente sus alabanzas tuvieron algo que ver en esta feliz decisión del monarca. El cargo de maestro de pajes suponía, además, una oportunidad para probar su valía en un lugar cercano al rey, lo que para él podría constituir una esperanza de obtener aún más favores. Además de este testimonio, el documento recoge una apostilla manuscrita de gran interés:

Este Sebastián Morzillo está ahora en Sevilla y es natural de aquí y un su hermano fraile de San Ysidro mochacho está preso en este Castillo [de Triana]. Y este Sebastián Morzillo también ha tenido conversación en San Ysidro (Pineda, 1994: 62).

Como vemos, en ella se insiste en que Sebastián Fox reside en Sevilla y añade un dato que no está presente en la declaración del fraile: Fox Morcillo había tenido contacto con el foco luterano de San Isidro, al que su hermano pertenecía. Al hilo de esta información, Ignacio J. García Pinilla (2012: 54) se pregunta si Sebastián no llevaría a su hermano alguna obra impresa, traída de los Países Bajos. Aunque no conservemos ningún dato fehaciente que lo pruebe, se trataba — como estudia García Pinilla (2012: 45-62) — de uno de los métodos con los que el foco luterano sevillano se alimentó de obras prohibidas, por lo que tampoco sería descabellado el considerarlo.

En último lugar, y antes de retomar las palabras de Fray Baltasar, quisiera atender a la referencia del libro de aquel Ceriolario, que no es otro que Furió Ceriol y su obra Bononia sive de libris in vernaculum linguam vertendis libri duo, considerado herético y causa de la prisión para el autor. Este grupo de heterodoxos defendió la obra de Ceriol, frente a las acusaciones que presenta Fray Baltasar, que le considera impío, redactor de pasquines antirreligiosos y amigo de alemanes ${ }^{69}$.

Las palabras de Fray Baltasar, distanciándose insistentemente del controvertido grupo, presentan ahora acusaciones de carácter general, que relacionan palabras injuriosas de los lovanienses contra la preceptiva de la Iglesia, concretamente en contra de los sacerdotes y la Inquisición:

Lo que yo puedo decir de él, de más de que era uno de los de la junta todo tiempo que estuvo allá, es que en las conversaciones particulares, así él como todos los de aquel escuela, eran prontos a decir mal del regimiento de los perlados de la Iglesia y que se les debían quitar sus rentas, pues ya son más tiranos que pastores; y tras esto se daban tras las religiones y los frailes, y muy muchas veces murmuraron del Sancto Oficio de la Inquisición de España, unas veces diciendo que no hera sino carnicería, y que había muchas veces juicios falsos; y que si una vez prendían un hombre, aunque no hubiese hecho, porque le habían de levantar algo, por que no

69. Tellechea (1963: 25-26). 
pareciese que lo habían prendido livianamente, y así otras mill bajezas que eran tan ordinarias y decíanlas tantos, que no me acuerdo particularmente de [h] ulano o [h] ulano [...] (Tellechea, 2007, vol. 4 (1): 351-352).

La desafección está pues muy presente en estas palabras, que nos permiten escuchar sin dificultad los ecos de ciertas tesis reformistas. Finalmente, las acusaciones se concretan en la persona de Morcillo, en cuyas palabras aspiramos las ansias de recuperación de un cristianismo primitivo, donde los votos de castidad y obediencia no tenían potestad:

Agora digo lo que se me acuerda, y es que un día estábamos juntos este Morcillo, que está aquí, en la cámara del Doctor Joverino y vino a plática tratar de los voctos. Y este Morcillo siguiendo a quien le pareció, dijo allí que no había más de 200 años que se usaba en la Iglesia obligarse a los religiosos a perpetua castidad y a obediencia, y así lo demás; y de aquí infería que antiguamente había más libertad. Yo le alegué lo que dize San Agustín en c. 3 De bono virginali, que Nuestra Señora hizo vocto de virginidad; y cómo prueba él que, a su ejemplo, en su tiempo, digo en tiempo de San Agustín y antes de él, muchas personas religiosas se dedicaban a Dios con aquella manera de sacrificio. Allí voceamos un poco sobre esto, y témome que sin provecho (Tellechea, 2007, vol. 4 (1): 352-353).

Si algo de luz ha arrojado el testimonio de fray Baltasar sobre la oscuridad de la vida de nuestro autor, este se ha encargado de probar que aún en 1558 estaba vivo en Sevilla, imposibilitando el supuesto naufragio de Lovaina a España. Ahora bien, del paradero de Morcillo una vez acabada esta declaración nada sabemos, toda la información se oscurece y, a la vez, se abre en miles de elucubraciones en las que podríamos, sin duda, deleitarnos.

Atendiendo a las cartas Languet, se puede observar — en ambas cartas — la referencia de un arzobispo de Toledo, que aún siendo sospechoso ante la Inquisición no fue condenado. Este arzobispo de Toledo no puede ser otro que Bartolomé de Carranza $^{70}$, apresado por la Inquisición el 22 de agosto de 1559. Es decir, si en la carta datada en 1550 contiene esta referencia posterior, hay que pensar en una errata en la fecha de la carta XvIII, que no puede haber sido escrita antes de 1559. Por lo tanto, no parece extraño que ambas cartas estuvieran escritas en 1560 y que en la XVIII, hubiera una errata en la tercera cifra del año de la fecha «1550» ${ }^{71}$. De tal manera que, a la luz de estos datos, tan solo el testimonio de la muerte de Fox en torno a 1560 parece verosímil. Para reforzar esta hipótesis podemos partir del razonamiento de Kuiper que se apoya en una referencia de Cornelio Valerio

70. Tellechea (2009-2012: 608-612).

71. Kuiper (1941: 200) señala que aunque Jöcher (1941, t. 3: 695) considere que Fox moriría en 1568 , parece increíble que un autor de su talla permaneciera en la oscuridad por más de diez años. Huiper se muestra partidario de seguir el testimonio de la carta de Languet. 
en su prólogo a Physicae, seu de naturae philosophia institutio, perspicue et breviter explicata (Amberes, 1566), para argumentar que el hispalense estaba ya muerto antes de $1566^{72}$.

Respecto a la invención por parte de Escoto de la fecha de muerte de Fox, debemos preguntarnos a qué se debe esta suposición. Espigares (1994: 231-232) abre toda una serie de interrogantes que conducen al lector hasta la tesis de que el naufragio fuera un invento para ocultar la supuesta condena, por parte de la Inquisición, de Fox Morcillo. Se apoya en un trabajo de Morel-Fatio en el que se estudia el ocultamiento deliberado, por parte de Escoto, de la muerte en la cárcel del humanista Pedro Galés. Sin embargo, Espigares no solo no tiene en cuenta las epístolas de Languet en este punto, sino que no las menciona en todo el trabajo. La existencia de estas dificulta la conjetura de Espigares, sin que se contradiga, por supuesto, la posibilidad del asesinato de Fox Morcillo por parte de la Inquisición.

En suma - a pesar de que los datos son confusos- lo más lógico sería pensar que Fox, tras las referidas acusaciones presentadas ante la Inquisición por fray Baltasar, huyera de nuevo a algún lugar de los Países Bajos. No obstante, parece ser que este barco naufragó, sin que el hispalense lograra escapar de la muerte ${ }^{73}$. No es extrańo pensar que la muerte de su hermano en 1559, considerando que su persona estaba también en el punto de mira del Santo Oficio, le empujara a escapar de España en aquel momento.

Vivir pasando desapercibido podría ser el resumen de todo el conjunto de datos contradictorios, declaraciones, juegos literarios y conjeturas que hemos espigado, para intentar ofrecer la poca pero inquietante información que conservamos sobre este velado y eminente humanista español, Sebastián [Morcillo] Fox.

72. Su argumento (Kuiper, 1941: 201) consiste en que Cornelio Valerio habla de Fox en pasado (fuit). Efectivamente la referencia se encuentra en las dos ediciones que he podido consultar de Physicae seu de nature philosofhia instiutio: «Sebastianus Foxius, vir summo ingenio et eruditione minime vulgari praestans (cum quo mihi permagna et domestica et diurna familiaritatis fuit» (la negrita es mía). Cornelio Valerio, Physicae seu de nature philosofhia institutio, Ex officina Christophori Plantini, Amberes. 1567, p. 3. El mismo texto se repite en la edición de Ex officina Christophori Plantini, Amberes, 1568, p. 3.

Este último lo he leído a partir de la digitalización que se ofrece en Google books: <http://books. google.es/books?id=0vU7AAAAcAAJ\&pg=PA4\&dq=Physicae+seu+de+nature+philosofhia+institu tio\&hl=es\&sa=X\&ei=G0ZzU6TAEazA7AaG7YGgCg\&ved=0CHYQ6AEwCQ\#v=onepage\&q= Physicae\%20seu\%20de\%20nature\%20philosofhia\%20institutio\&f=false>. No he localizado ningún ejemplar de la primera edición de Amberes, 1566, que ya da por perdida Pineda (1994: 65); sin embargo, el razonamiento de Kuiper (1941: 201), —ya expuesto- sigue siendo defendible a partir de estas dos ediciones, pues ambos prólogos conservan la fecha de la primera edición de 1566 y es en el prólogo donde se inserta el fragmento ya transcrito en el que se habla de Fox en pasado.

73. Pineda (1994: 57-58) considera igualmente, aunque conociendo solo una de las dos cartas de Languetus, que el hundimiento del barco se dio cuando Fox volvía a los Países Bajos y no — como defendía Escoto- de vuelta a España desde Lovaina. 


\section{Hacia una biografía completa de Fox Morcillo}

Con el estudio que hemos abordado a lo largo de estas páginas hemos trazado una biografía exhaustiva del humanista español. Aunque no podamos cerrar el capítulo de la vida de Fox Morcillo, no quisiera dejar de destacar los caminos transitados en este estudio y las nuevas aproximaciones a las que nos ha llevado. En primer lugar, para el estudio de las fuentes documentales sobre la figura de Sebastián Fox Morcillo, hemos adoptado una clasificación binaria que nos permitiera valorar el grado de veracidad de la información recabada:

Fuentes procedentes del propio autor. De ellas solo se conservan: las que se contienen en las notas marginales de algunos ejemplares de su obra dedicados a la nobleza de la época (conservados en la Biblioteca del Monasterio de El Escorial y en la Biblioteca Nacional de Espańa). Además, de entre los ejemplares escurialenses, los que pertenecieron a Arias Montano nos dejan otra fuente primaria de su vida, aunque a partir de una cita en el tercer inventario de sus bienes: la noticia de la cédula de empeño de los libros firmada por Fox en Sevilla el 7 de diciembre de $1558^{74}$. Otra fuente importante es la citada carta de Fox al cardenal Granvela (Real Biblioteca, 2005). No obstante, respecto a la información contenida en su obra literaria, hemos postulado la necesidad de estudiar con cautela cualquier dato biográfico contenido en ella, como elemento susceptible de ser literaturizado, aunque el personaje de la obra en cuestión adopte el nombre del propio autor, como sucede en el pasaje de De imitatione ${ }^{75}$.

Fuentes procedentes de testimonios coetáneos al autor. La carta XVI - tan solo citada por Lueben (1914) — y la carta XviII del epistolario de Languet (1699, II: 40-42 y 45-47), dirigidas a Philippo Melanchthon la primera y a Ulricho Mordisio la segunda; el testimonio de Andrés Escoto en Hispaniae Bibliotheca, y por último, la más reveladora: la declaración de Fray Baltasar Pérez en el llamado Proceso de Carranza.

En segundo lugar, el estudio propiamente biográfico nos ha permitido, además de trazar una sistematización de la biografía de Sebastián Fox Morcillo, depurar errores que, aun habiendo sido señalados por varios estudiosos, se seguían repitiendo por falta de una lectura organizada y completa de la bibliografía.

Por otro lado, hemos afianzado la posibilidad de que la fecha de nacimiento fuera 1526. Es decir, el diálogo De iuventute, donde se menciona la edad del personaje que lleva su nombre, se ubica — como expresa González de la Calle (1903: 13-15) — junto con el hecho histórico citado: la llegada de Felipe II a Inglaterra para casarse con María Tudor, acontecimiento que tuvo lugar en 1554. No parce inverosímil pensar que Fox adecuara - como parte de la estrategia argumentativa - la edad del personaje de Sebastián Fox a la que él mismo tenía en 1554 y no en 1556, como la mayoría de la crítica ha señalado.

74. Rodríguez-Moñino (1928).

75. Pineda (1994: 134 y 182). 
Respecto al hecho más problemático, el de su muerte, si bien no se ha podido avanzar conclusiones definitivas en este estudio, sí creo que gracias a la sistematización de lo ya estudiado se ha podido encaminar su explicación hacia perspectivas más certeras. En este sentido, el testimonio olvidado de la carta XVI de Languet ha sido analizado a la luz de la referencia que incluyen las dos cartas a un arzobispo de Toledo - que hemos identificado con Bartolomé de Carranza, quien aún habiendo sido sospechoso ante la Inquisición no fue condenadoPor ello, hemos concluido que, puesto que Carranza fue apresado por la Inquisición el 22 de agosto de 1559, no parece extraño que ambas cartas estuvieran escritas en 1560 y que en la XVIII, hubiera una errata en la tercera cifra del año de la fecha «1550». Estos datos, junto a Cornelio Valerio (1567: 3) en su prólogo a Physicae, seu de naturae philosophia institutio, perspicue et breviter explicata nos han llevado a postular que tan solo el testimonio de la muerte de Fox en torno a 1560 parece verosímil. Sin embargo, no podemos aseverar — con los datos de los que disponemos por el momento- que Fox Morcillo muriera a manos de la Inquisición, ni en el citado naufragio, aunque tal vez esta parezca la causa más plausible. 


\section{Bibliografía}

Ames, John, Antiquities or The History of Printing in England, Scotland and Ireland, Edited by Thomas Frognall Dibdin (1810-1819), London, printed by W. Bulmer and Co. Cleveland Row, St. James, 1819. Cito a partir de la ed. facsímil: Hildesheim, Georg Olms Verlagsbuchhandlung, 1969, 4 vols.

Antonio, Nicolás, Bibliotheca Hispana Nova, sive hispaniorum scriptorum qui ab anno MD.ad MDCLXXXIV floruere notitia..., Madrid, Apud Joachimum de Ibarra [et] Apud Viduam et Heredes Joachimi de Ibarra., 1783-1788, 2 t.

Archivo General de Indias, Catálogo de pasajeros a Indias durante los siglos XVI, XVII y XVIII, redactado por el personal facultativo del Archivo General de Indias bajo la dirección del Director del mismo Don Cristóbal Bermúdez Plata, Sevilla, CSIC-Patronato Menéndez y Pelayo-Instituto Gonzalo Fernández de Oviedo , 1940-1946, 5 vols.

Arana de Varflora, Fermín, Hijos de Sevilla. Ilustres en santidad, letras, armas, artes, ò dignidad. Dalos al público. Colocados por orden alfabético, Sevilla, Vázquez e Hidalgo, 1791.

Baillet, Adrien, Des enfants devenus célèbres par leurs études ou par leurs écrits. Traité historique, Paris, Chez Antoine Dezallier, ruë S. Jacques, a la Couronne d'Or, 1683.

—, «Tomo 6. Les enfants Celebres et les Auteurs Deguisés», en Jugements des savans sur les principaux ouvrages des auteurs par Adrien Baillet. Revîs corrigés, et augmentés par $M$ de la Monnoye de la Academie Françoise, Paris, Charles Moette, ruë de la Bouclerie, près le Pont $S$. Michel, etc. 1722.

BÉcares Botas, Vicente, «Fernando de Arce es Hernando de la Torre», Pliegos de Bibliofilia, 23, (2003), págs. 69-74.

Bores y LLEDó, José, «Sebastián Fox Morcillo. Sucinta noticia biográfica de este filósofo y juicio crítico de sus obras», en Real Academia Sevillana de Buenas Letras, Certamen Literario celebrado el 15 de abril de 1884. Obras Premiadas, Sevilla, Imp. de E. Rasco, 1884, págs. 261-293.

Brucker, Johann Jakob, Historia critica philosophiae, Lipsiae, Apud Bernh. Christoph. Breitkopf, 1742-1767, 6 t.

Bulens, Charles (ed.), L'Université de Louvain. Coup d'ail sur son Histoire et ses institutions. 1425-1900, Bruxelles, Imprimerie scientifique, 1900.

Cabrero Fernández, Fernando, La aportación de Marcelino Menéndez Pelayo a la Filosofía Española, Tesis doctoral dirigida por Jaume Mensa i Valls, Barcelona, Universitat Autònoma de Barcelona, 2012, accesible on-line, <http:// www.tdx.cat/bitstream/handle/10803/113557/fcflde1.pdf?sequence=1 $>$, consultado el 23/04/2015.

Calvete de Estrella, Juan Christóbal, El felicissimo viaje del muy alto y muy poderoso Principe don Phelippe, intr. José Luis Gonzalo Sánchez-Molero et al. y ed. de Paloma Cuenca, Madrid, Sociedad Estatal para la Conmemoración de los Centenarios de Felipe II y Carlos V, 2001. 
Cantarero de Salazar, Alejandro, "La mimesis conversacional en el corpus de diálogos de Sebastián Fox Morcillo: introducción a su estudio literario», eHumanista, 29, (2015a), págs. 305-341.

—, "Aproximación a la tradición editorial de la obra de Sebastián Fox Morcillo: Primer repertorio tipobibliográfico», Camenae, 17, (2015b), págs. 1-31.

Caro, Rodrigo, Varones insignes en letras naturales de la Ilustrisima Ciudad de Sevilla, estudio y ed. crítica de Luis Gómez Canseco, Sevilla, Diputación Provincial de Sevilla, 1992.

Castrillo Benito, Nicolás, El «Reginaldo Montano»: Primer libro polémico contra la Inquisición española, Madrid, CSIC, Centro de Estudios Inquisitoriales, 1991.

Cortijo Ocaña, Antonio, Teoría de la Historia y Teoría política en Sebastián Fox Morcillo. De historiae institutione dialogus. Diálogo de la enseñanza de la Historia (1557), Alcalá de Henares, Servicio de Publicaciones de la Universidad de Alcalá de Henares-Servicio de Archivo y Publicaciones de la Diputación de Sevilla, 2000.

Domínguez Ortíz, Antonio, «Los conversos de origen judío después de la expulsión", en Carmelo Viñas y Mey (dir.), Estudios de Ha social de España, Madrid, DPTO. de Ha Social de España del Instituto «Balmes» de Sociología-CSIC, 1955, III, págs. 224-431.

Espigares Pinilla, Antonio, La cuestión del honor y la gloria en el humanismo del siglo XVI a través del Gonsalus de Ginés de Sepúlveda y de De Honore de Fox Morcillo, Tesis doctoral, Universidad Complutense, Madrid, 1994.

—, "Teoría y práctica de la imitación ciceroniana en el diálogo De iuventute de Sebastián Fox Morcillo», en Trinidad Arcos Pereira, Jorge Fernández López y Francisca Moya del Baño (eds.). 'Pectora mulcet' Estudios de Retórica y Oratoria latinas, Logrońo, Instituto de Estudios Riojanos, Ayuntamiento de Calahorra, 2009, 2, págs. 799-816.

—, «Fox Morcillo, Sebastián», en Juan Francisco Domínguez (ed.), Diccionario biográfico y bibliográfico del humanismo español (siglos XV-XVII), Madrid, Ediciones Clásicas, 2012, págs. 311-314.

Fox Morcillo, Sebastián, De naturae philosophia seu de Platonis et Aristotelis consensioni, Lovaina, Apud Petrum Colonaeum, 1554a.

—, «De Philosophici studii ratione Ad Franciscum fratrem liber», en De naturae philosophia seu de Platonis et Aristotelis consensione libri v, Lovanii, Apud Petrum Colonaeum, 1554b, págs. 165-203.

-, De Inventute, Basileae, Per Ioannem Oporinum, [Colofón: Per Martinum Stellam, 1556, Mense Martio].

García Pinilla, Ignacio J., "Lectores y lectura clandestina en el grupo protestante sevillano del siglo XVI», en María José Vega e Iveta Nakládalová (eds.), Lectura y culpa en el siglo XVI. Reading and Guilt in the 16th Century, Barcelona, Universitat Autònoma de Barcelona-Servei de Publicacions, 2012, págs. 45-62. 
Gestoso y Pérez, José, Ensayo de un diccionario de artifices que florecieron en Sevilla, desde el siglo XIII al XVIII inclusive, Sevilla, 1899-1900, 3 vols.

Gil Fernández, Juan, Los conversos y la Inquisición sevillana: ensayo de prosopografía, Sevilla, Fundación el Monte, 2000-2003, 8 vols.

—, "Marcial en España», Humanitas, 56, (2004), págs. 225-326.

González de la Calle, Pedro Urbano, Sebastián Fox Morcillo. Estudio histórico-crítico de sus doctrinas, Madrid, Imprenta del Asilo de Huérfanos del Sagrado Corazón de Jesús, 1903. [Contiene una traducción del diálogo De iuventute en las págs. 253-372].

GonZalo García, R. Consuelo, Las relaciones de sucesos en bibliotecas particulares madrileñas. Aportaciones a un catálogo descriptivo, dir. Mercedes Fernández Valladares, Tesis doctoral, Universidad de Salamanca, 2014.

Gonzalo SÁnchez-Molero, Jose Luis, «Las obras del Filósofo Sebastián Fox Morcillo en la bibliofilia española del siglo Xvı», Pliegos de Bibliofilia, 19, (2002), págs. 21-42.

- Felipe II. La educación de un "felicísicmo príncipe» (1527-1545), Madrid, CSIC-Ed. Polifemo, 2013.

Guillén, Claudio, «Un padrón de conversos sevillanos (1510)», Bulletin Hispanique, 65, (1963), 1-2, págs. 49-98.

Illanes, José Luis y Saranyana, Josep Ignasi, Historia de la Teología, Madrid, Biblioteca de autores cristianos, 1995.

JECKER, Mélanie, «Une précieuse découverte: un recueil de textes aristotéliciens réunis par Sebastián Fox Morcillo et annotés de sa main (BNE R/25106)», e-Spania. Revue interdisciplinaire d'études hispaniques médiévales et modernes, 13 de junio de 2012, Hélène Thieulin Pardo (dir.), <http://e-spania.revues. org/21500>, consultado el 23/04/2015.

Jöcher, Christian Gottlieb, Allgemeines Gelehrten-Lexicon: darinne die Gelehrten aller Stäende sowohl männ-als weiblichen Geschlechts, welche vom Anfange der Welt bis auf die jetzige Zeit gelebt, Leipzig, In Joham Friedrich Gleditschens Buchhandlung, 1750-1751, 4 vols.

Languetus, Hubertus, Epistolae secretae ad principem suum Agustum, Halae Hermunduror, impensis Ioh. Friderici Zeitleri Hene. Georgii Musselii, 1699.

Laverde Ruiz, Gumersindo, «Fox Morcillo. Discurso inaugural del curso Académico de 1884 a 1885 en Universidad de Santiago, por el Dr. D. Gumersindo Laverde Ruiz. Oficina tipográfica de José Ma Paredes», en Marcelino Menéndez Pelayo, La ciencia española, tomo 1, Madrid, Librería General de Victoriano Suárez, 1933, págs. 222-223.

Lueven, Robert, Sebastian Fox Morcillo und seine Naturphilosophie. Anhang Die Staatsphilosophie des Sebastian Fox Morcillo von Marin Honecker, Bonn, Verlag von Peter Hanstein, 1914.

Matute y Gaviria, Justino, Hijos de Sevilla, señalados en santidad, letras, artes, armas, ó dignidad, Sevilla, Oficina del Orden, 1886. 
Méndez Berjarano, Mario, Diccionario de escritores, maestros y oradores naturales de Sevilla y su actual provincia, Sevilla, Tipografía Gironés, 1922.

Menéndez Pelayo, Marcelino, Historia de los heterodoxos españoles. Erasmistas y protestantes. Sectas misticas. Judaizantes y Moriscos. Artes mágicas, México, Editorial Porrúa, 1982.

-, Epistolario. ed. al cuidado de Manuel Revuelta Sañudo, Madrid, Fundación Universitaria Española, 1982-1991. 23 vols. Citado a partir de: Epistolario [Recurso electrónico]/ Marcelino Menéndez Pelayo, en Menéndez Pelayo digital: obras completas, epistolario y bibliografía al cuidado de Manuel Revuelta Sañudo, Madrid, Fundación Ignacio Larramendi-Fundación MAFRE, 2009, <http://www.larramendi.es/i18n/consulta/registro.cmd?id=956>, consultado el 21/ 04/2015.

Mireo, Auberto, Elogia Belgica sive illustrium belgi scriptorum, qui nostram patrumque, vel Ecclesiam Dei propugnarunt, vel disciplinas illustrarunt, vitae breviter commemoratae, Antuerpiae, Apud Davidem Martinium, 1609.

Monтoto, Santiago (ed.), Justas poéticas sevillanas del siglo XVI (1531-1542). Reimpresas por primera vez del ejemplar único, con un estudio preliminar de Santiago Montoto, Valencia, Castalia, 1955.

Morales Padrón, Francisco, «La Sevilla del Quinientos», en Dimas Borrego Paín (coord.), Historia de Sevilla, Salamanca, Universidad de Sevilla, 1992, págs. 227-267.

Naudé, Gabriel, Bibliographia Politica, Venetiis, Francisco Baba, 1633.

PIKe, Ruth, «De converso origin of Sebastián Fox Morcillo», Hispania. A journal devoted to the interest of the teaching of Spanish and Portuguese, 51, (1968), 4, págs. 877-882.

—, Aristócratas y comerciantes. La sociedad sevillana en el siglo XVI español, trad. de Bárbara Mecshane y Javier Alfaya, Barcelona, Ariel, 1978.

PINEDA, Victoria, La imitación como arte en el siglo XVI español (Con una edición y traducción del diálogo De imitatione de Sebastián Fox Morcillo), Sevilla, Diputación Provincial de Sevilla, 1994.

—, «Fox Morcillo, Sebastián», en Real Academia de la Historia, Diccionario Biográfico Español, tomo XX, Madrid, R.A.H, 2009-2012, págs. 532-534.

Real Biblioteca, "Fox Morcillo, comentarista de Platón y anticuario», Avisos de la Real Biblioteca, Año XI, N. 41 (abril - junio, 2005). <http://avisos. realbiblioteca.es/?p=article\&aviso=49\&art=893 >>, consultado el 21/04/2015.

Robledo Estaire , Luis, «El lugar de la música en la educación del príncipe humanista», en Virginie Dumanoir (dir.), Música y literatura en la España de la Edad Media y del Renacimiento, Madrid, Casa Velázquez, 2003, págs. 1-19.

Rodríguez Marín, Francisco, Nuevos datos para las biografías de cien escritores de los siglos XVI y XVII, Revista de Archivos, Bibliotecas y Museos [Anejo], Madrid, Ti. de la Revista de Archivos, Bibliotecas y Museos, 1923, pág. 64.

Rodríguez-Moñıno, Antonio, «La biblioteca de Benito Arias Montano. Noticias y documentos para su reconstrucción (1548-1598)», Revista del Centro 
de Estudios Extremeños, tomo II, Homenaje a Benito Arias Montano, (1928), págs. 555-598.

Schillings, Arnold, Matricule de l'Université de Louvain, Bruxelles, Palais des Académies, 1961, vol. IV (Février 1528-Février 1569).

Sснотт, Andreas, Hispaniae Bibliotheca seu de academiis ac bibliothecis. Item elogia et nomenclator...,Francofurti, Apud Claudium Marnium et haeredes Ioan. Aubrii, 1608, t. III.

SkINnER, Vicente, $A$ discovery and playne declaration of sundry subtill practises of the Holy Inquisition of Spayne... by Reginaldus Gonsalvius Montanus and lately translated, London, Iohn Day, dwelling over Aldersgate beneath $S$. Martines and are to be solde at his shop under the gate, 1569 .

Tellechea Idígoras, «Españoles en Lovaina 1551-8. Primeras noticias sobre el bayanismo", Revista Española de Teología, 23, (1963), págs. 21-33.

—, «Españoles en Lovaina 1557», en Werner Thomas y Robert A. Verdonk (eds.), Encuentros en Flandes, Louvain, Leuven University Press y Fundación Duques de Soria, 2000, págs. 132-155.

-, El arzobispo Carranza. "Tiempos recios» IV. 1 Cartas boca arriba. La Crisis religiosa española de 1558-1559 a través de cartas contemporáneas, Salamanca, Publicaciones Universidad Pontificia- Fundación Universitaria Española, 2007.

—, "Carranza de Miranda, Bartolomé», en Real Academia de la Historia, Diccionario Biográfico Español, tomo XI, Madrid, R.A.H, 2009-2012, págs. 608-612.

TRUman, R.W, «Sebastián Fox Morcillo`s De regni regisque institutione (Anterp, 1556): Humanist Approaches to Empirism», en Acta conventus neo-latini sanctandreani: proceedings of the Fifth International Congress of Neo-Latin Studies: St. Andrews 24 August to 1 September 1982, Binghamton-New York, Center for Medieval and Early Renaissance Studies-University Center at Binghamton, 1986, págs. 283-290.

Valerio, Cornelio, Physicae seu de nature philosophia institutio, Ex officina Christophori Plantini, Anvers, 1567.

Vocht, Henry de, History of the foundation and rise of the Collegium Trilingue Lovaniense, 1557-1560, Louvain, Bibliothèque de l'Université-Bureaux du Recueil 1951-1955, 4 vols. 